\author{
Marquette University \\ e-Publications@Marquette
}

Biological Sciences Faculty Research and

Publications

Biological Sciences, Department of

3-2001

\title{
Contributions of Identifiable Neurons and Neuron Classes to Lamprey Vertebrate Neurobiology
}

James T. Buchanan

Marquette University, james.buchanan@marquette.edu

Follow this and additional works at: https://epublications.marquette.edu/bio_fac

Part of the Biology Commons

\section{Recommended Citation}

Buchanan, James T., "Contributions of Identifiable Neurons and Neuron Classes to Lamprey Vertebrate Neurobiology" (2001). Biological Sciences Faculty Research and Publications. 201.

https://epublications.marquette.edu/bio_fac/201 
Marquette University

e-Publications@Marquette

\title{
Biological Sciences Faculty Research and Publications/College of Arts and Sciences
}

This paper is NOT THE PUBLISHED VERSION; but the author's final, peer-reviewed manuscript. The published version may be accessed by following the link in the citation below.

Progress in Neurobiology, Vol. 63, No. 4 (March 2001): 441-466. DOI. This article is (C) Elsevier and permission has been granted for this version to appear in e-Publications@Marquette. Elsevier does not grant permission for this article to be further copied/distributed or hosted elsewhere without the express permission from Elsevier.

\section{Contributions of Identifiable Neurons and Neuron Classes to Lamprey Vertebrate Neurobiology}

James T. Buchanan

Department of Biology, Marquette University, P.O. Box 1881, Milwaukee, WI

\begin{abstract}
Among the advantages offered by the lamprey brainstem and spinal cord for studies of the structure and function of the nervous system is the unique identifiability of several pairs of reticulospinal neurons in the brainstem. These neurons have been exploited in investigations of the patterns of sensory input to these cells and the patterns of their outputs to spinal neurons, but no doubt these cells could be used much more effectively in exploring their roles in descending control of the spinal cord. The variability of cell positions of neurons in the spinal cord has precluded the recognition of unique spinal neurons. However, classes of nerve cells can be readily defined and characterized within the lamprey spinal cord and this has led to progress in understanding the cellular and synaptic mechanisms of locomotor activity. In addition, both the identifiable reticulospinal cells and the various spinal nerve cell classes and their known synaptic interactions have been
\end{abstract}


used to demonstrate the degree and specificity of regeneration within the lamprey nervous system. The lack of uniquely identifiable cells within the lamprey spinal cord has hampered progress in these areas, especially in gaining a full understanding of the locomotor network and how neuromodulation of the network is accomplished.

\section{Abbreviations}

AHP, after-spike hyperpolarization

$\mathrm{B}_{1-4}$, identifiable Müller cells of Bulbar region

$\mathrm{CC}$, contralaterally and caudally projecting interneuron

DC, dorsal cell

DA, dopamine

EC, edge cell

eCC, excitatory CC interneuron

EIN, excitatory interneuron

EPSP, excitatory postsynaptic potential

$\mathrm{F}-\mathrm{I}$, frequency versus current relationship

GABA, gamma-aminobutyric acid

$\mathrm{Gl}$, giant interneuron

HRP, horseradish peroxidase

5-HT, 5-hydroxytryptamine

$I_{1-2}$, identifiable Müller cells of the Isthmic region

iCC, inhibitory CC interneuron

IIN, inhibitory interneuron

IPSP, inhibitory postsynaptic potential

LIN, lateral interneuron

$M_{1-3}$, identifiable Müller cells of the Mesencephalon

$\mathrm{MN}$, motoneuron

Mth, Mauthner cell

NMDA, $N$-methyl-d-aspartate

PSP, postsynaptic potential

$\mathrm{RRN}$, rhombencephalic reticular nucleus

$V R$, ventral root

\section{Introduction}

This review will evaluate the contributions that identifiable neurons in the brainstem and identifiable neuron classes in the spinal cord have made to lamprey vertebrate neurobiology, especially with regard to the origin and control of locomotion and to neuronal regeneration.

As in other lower vertebrates, the lamprey brainstem contains uniquely identifiable reticulospinal cells. These are the well-known Mauthner cells with crossed descending axons and several pairs of Müller cells, which are large reticulospinal neurons with ipsilateral descending axons. The Müller cells of the lamprey have been exploited in numerous studies due to their large size and ease of microelectrode impalement. The identifiability of these cells has been exploited in several types of experiments and has been particularly useful in characterizing patterns of sensory inputs, the patterns of output to spinal neurons, and in studies of regeneration.

As yet, however, no uniquely identifiable neurons have been found in the lamprey spinal cord, but nerve cell classes are readily defined and characterized on the basis of a variety of morphological and physiological criteria. 
Some of these classes consist of relatively few cells and may be candidates for uniquely identifiable neurons. Other classes have numerous members due to rather broad class definitions and will require further refinements in their class distinctions. The ease in characterizing cell classes in the lamprey spinal cord has been important in investigations of the neuronal network underlying locomotion. While some progress has been made in determining the structure and function of this spinal network, much remains to be done. The inability to uniquely identify nerve cells or to define nerve cells classes with precision has hampered progress in comparison to invertebrate preparations.

\section{Experimental preparations of the lamprey}

The lampreys and hagfish are the most primitive living vertebrates, and these jawless fishes exhibit a number of morphological similarities to the earliest vertebrates in the fossil record. Nonetheless, the lamprey nervous system is organized along the vertebrate plan and is especially well suited for in vitro neurobiological analysis. The lamprey brain and spinal cord survive well when isolated, displaying normal electrophysiological properties for several days after isolation and also displaying the neuronal correlate of reflexes and swimming behavior ('fictive' swimming). The brainstem and spinal cord are particularly useful for in vitro studies because they are relatively transparent due to the lack of myelin, and this transparency allows visualization of nerve cell bodies and axons using a stereomicroscope.

The typical in vitro preparation of the lamprey spinal cord is the spinal cord/notochord preparation in which the dorsal surface of the spinal cord is exposed while the ventral surface is left attached to the bottom of the spinal canal and the notochord. In this preparation, the notochord is usually split down its ventral midline, spread laterally and pinned to the bottom of the experimental chamber. This allows for good stability of the spinal cord and easy access to the ventral roots for extracellular recording of motor activity. The length of spinal cord used in spinal cord/notochord preparations is often 10-20 segments ( $25-50 \mathrm{~mm}$ in $300-\mathrm{mm}$ long animals). Other common preparations include (1) the brainstem/spinal cord preparation in which the brainstem is left attached to spinal cord and (2) the completely isolated spinal cord in which the spinal cord is removed from the notochord.

\section{Identifiable reticulospinal neurons}

In addition to the Mauthner cells, which have been well studied in teleost fishes (Eaton et al., this volume), the lamprey brainstem contains uniquely identifiable reticulospinal neurons known as the Müller cells. The identifiability of these cells has made them popular subjects for a variety of studies. These studies have contributed to our understanding of how the brainstem controls spinal circuitry by allowing a detailed mapping of the patterns of contacts between the Müller cells and different classes of spinal neurons. The identifiability of Müller cells has also allowed a characterization of their different inputs from sensory and motor systems and the pharmacology of these inputs. In addition, identifiable synapses from the Müller cells have been exploited to provide detailed ultrastructural characterizations of their synaptic contacts with spinal neurons.

As shown by Rovainen, using several species of lampreys, the cell bodies of the Müller cells can be recognized as a series of at least nine symmetrical pairs on the basis of their positions, sizes, and shapes (Rovainen, 1967a, Rovainen et al., 1973, Rovainen, 1978). Three pairs are located in the mesencephalon ( $\left.\mathrm{M}_{1-3}\right)$, two in the anterior rhombencephalic reticular nucleus or isthmic region $\left(I_{1-2}\right)$, and four in the middle rhombencephalic reticular nucleus or bulbar region $\left(B_{1-4}\right)$ (Fig. $1 A$ ). Many other reticulospinal neurons also exist in these regions, but due to their smaller sizes and their variabilities in position from preparation to preparation, unique identification of these cells is less certain. Even among Müller cells, there is variability in the positions and numbers of the cells making unique identification difficult in some preparations (Rovainen, 1967a, compare left and right sides in Fig. 1A). There is a great deal of similarity between the pattern of large reticulospinal cells in 
lamprey and the patterns revealed in the best-studied teleosts, the zebrafish (Kimmel et al., 1982, Metcalfe et al., 1986, Lee and Eaton, 1991) and the goldfish (Lee et al., 1993).
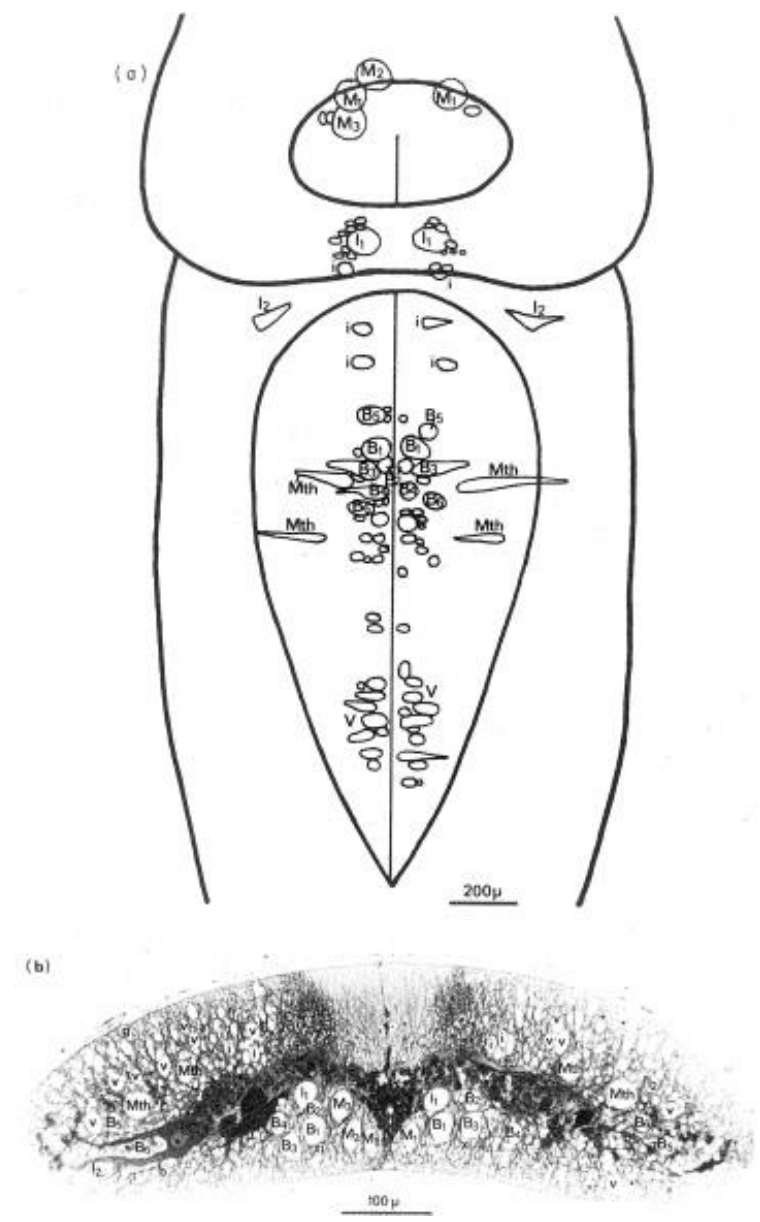

Fig. 1. Uniquely identifiable reticulospinal neurons in the lamprey. (a) Sketch of the positions of the Müller and Mauthner cells in the lamprey brainstem. The numbered cells are those that are reliably identifiable from preparation to preparation. Note however the variability in presence and positions of the cells when comparing the two sides. M, mesencephalic Müller cells; I, isthmic Müller cells of the anterior rhombencephalic reticular nucleus (RRN); i, smaller reticulospinal cells of the Isthmic region; B, bulbar Müller cells of the middle RRN; V, 'Vagal' reticulospinal cells of the posterior RRN; Mth, Mauthner Cells. (b) Micrograph of a transverse section of the spinal cord with the Müller and Mauthner axons labeled after identification using serial tracing (from Rovainen 1982; used with permission of publisher).

Many electrophysiological studies have made use of the Müller cells because their large size (up to $150 \mu \mathrm{m}$ in diameter) makes them relatively easy to find and to impale with intracellular microelectrodes. However, in most of these studies, the Müller cells have not been uniquely identified by the investigators due mainly to the difficulty in visualizing the Müller cells, especially in the adult preparation. In larval lampreys, the Müller cells are more clearly visible, so that their overall positional pattern can be discerned and individual cells more readily recognized. In the adult lamprey brainstem, however, the Müller cells can be seen only faintly. This difficulty can be overcome by making intracellular injections of Fast Green into each of the Müller cells by impaling and injecting dye into cell bodies in the brainstem regions where the Müller cells are found (Buchanan, 1982). An example of a recent electrophysiological study exploiting the identifiability of larval Müller and Mauthner cells is that of Rouse et al. (1998). They characterized the firing properties of these cells and reported distinct 
differences among the cell types, especially in their tendencies to display a delay in the latency to the first spike following a hyperpolarization, a pattern consistent with the presence of an A current.

The axons of Müller cells are unmyelinated and convenient for electrophysiological analysis because of their large sizes (40 $\mu \mathrm{m}$ in diameter) and their stereotyped positions in the spinal cord which allows some of them to be identified with fair reliability in the spinal cord/notochord preparation (Fig. 1B) (Rovainen, 1967a). The Müller cell axons descend ipsilaterally into the spinal cord, where they make combined en passant electrical/chemical excitatory synapses upon spinal neurons. Recent studies have exploited the large size of Müller axons to investigate the mechanisms of neurotransmitter release (Gad et al., 1998).

As first shown by Rovainen (1974b), each class of spinal neurons receives inputs from a characteristic subset of the Müller cells. The lateral interneurons, a class of large inhibitory spinal interneurons with descending ipsilateral axons (Section 4.3), reliably receive input from the Müller cells $B_{2-4}$ but only rarely from other Müller cells (Rovainen, 1974b). Similarly, the existence of three subdivisions within the broad class of cells called CC interneurons (cells with a contralaterally and caudally projecting axon) was proposed on the basis of the patterns of input that individual CC interneurons received from Müller cells shown with paired intracellular recordings (Buchanan, 1982) (Section 4.4). Thus, the patterns of Müller cell inputs to spinal neurons have proven useful for classifying postsynaptic cell classes.

Two spinal cell classes, the edge cells and the giant interneurons (4.7 Edge cells, 4.8 Giant interneurons), receive Müller cell input only from the $I_{2}$ cell. The axon of the $I_{2}$ Müller cell has been called the 'bursting' axon because it receives excitatory chemical input in the spinal cord and fires a burst of action potentials either when the isolated spinal cord is electrically stimulated (Rovainen, 1967a, Rovainen, 1974b) or when the skin of the animal is stimulated (Teräväinen and Rovainen, 1971) in the absence of the brainstem. The I2-to-giant interneuron synapse is a combined electrical/chemical excitatory synapse, and its ultrastructure has been studied extensively by Christensen. An interesting result of these studies is that while a single $I_{2}$ axon makes multiple dendritic contacts over a wide range of physical distances from a giant interneuron soma, the distances of these contacts in electrotonic length constants are fairly constant from synapse to synapse (Christensen and Teubl, 1979a, Christensen and Teubl, 1979b, Christensen, 1983). Recently, it has been demonstrated that other Müller axons, as well as the Mauthner axons, also receive excitatory and inhibitory synaptic inputs (Cochilla and Alford, 1997).

Despite their unique identifiability, it is not yet possible to define the function of Müller cells much beyond the general statement that they are involved in sensorimotor integration. Clearly, Müller cells can affect motor output via their excitatory synapses upon spinal motoneurons and premotor interneurons. Stimulation of single identified Müller cells at high frequency can initiate body or fin movements, and these patterns are fairly reproducible from animal to animal (Rovainen, 1967a). For example, stimulation of the $\mathrm{M}_{3}$ or $\mathrm{I}_{1}$ Müller cells produces flexion of the dorsal fins to the opposite side, indicating an activation of contralateral fin motoneurons. Stimulation of individual Müller cells during swimming activity in the spinal cord/notochord preparation can change both the intensity of ventral root bursts and the cycle period of the swim rhythm. Typically, ipsilateral ventral root bursts are strengthened, while contralateral bursts are weakened, and the cycle period of fictive swimming increases. The strength of these actions varies among the identified Müller cells, and such responses may be involved in steering control (Buchanan and Cohen, 1982).

The idea that Müller cells provide ongoing control of the spinal cord pattern during swimming is supported by the observation that Müller cells are themselves active during fictive locomotion. The membrane potentials of Müller cells exhibit rhythmic modulation during fictive swimming, with a tendency to be co-active with rostral ipsilateral ventral roots (Kasicki and Grillner, 1986, Kasicki et al., 1989). Müller cells located closer to the spinal cord exhibit the strongest oscillations suggesting that the activity originates from ascending spinobulbar 
neurons. In spite of their activity during fictive swimming and their ability to modify the output of the locomotor network, the Müller cells do not appear to be critical for the initiation of locomotor activity. This conclusion is based upon the observation that lesions of the middle axon tracts, where most of the Müller axons descend in the spinal cord (Fig. 1B), do not affect locomotor initiation from the brainstem, whereas lesions of the lateral axon tracts, where reticulospinal axons from cells of the posterior rhombencephalic reticular nucleus are found, have much stronger effects (McClellan, 1988).

The Müller cells receive a wide range of sensory inputs from the cranial nerves and the spinal cord (Wickelgren, 1977). Rovainen (1979a) examined the patterns of vestibular input to individual reticulospinal cells by stimulating vestibular nerves while recording intracellularly from identified Müller and Mauthner cells. Some of these cells received reproducible, short-latency inputs that were consistently found from preparation to preparation, while other cells showed less consistent inputs. For example, the $\mathrm{M}_{3}$ and $\mathrm{I}_{1}$ cells received a specific, reproducible pattern of inputs consisting of inhibition from the ipsilateral vestibular nerve and excitation from the contralateral vestibular nerve. These two cells also showed consistent excitation to downward roll to the contralateral side and to nose-up rotation suggesting that they are involved in specific vestibulospinal reflexes. Most Müller cells, however, showed only longer latency responses with greater variability to vestibular nerve stimulation, making their participation in specific vestibular reflexes less likely (Rovainen, 1979a). Various Müller cells also showed distinct differences in their responses to vibrational stimuli (Currie and Carlsen, 1987a, Currie and Carlsen, 1987b).

Müller cells have often been the subject of study of neurotransmitter actions, and in some of these studies the Müller cells have been uniquely identified. For example, using identified Müller cells, Matthews and Wickelgren (1979) found a difference between the responses of $M_{1-3}$ cells versus the $I_{1}$ cell to the inhibitory neurotransmitters GABA and glycine: the soma of the $\mathrm{I}_{1}$ cell responded to glycine while the somata of $\mathrm{M}_{1-3}$ did not. Similarly, inhibitory postsynaptic potentials (IPSPs) recorded from the somata of these cells also exhibited different sensitivities to strychnine: the IPSPs in $I_{1}$ were blocked by low strychnine concentrations while the IPSPs in $\mathrm{M}_{1-3}$ were not affected. In studies of Müller cell output synapses, the chemical excitatory synapses were blocked by excitatory amino acid antagonists and exhibited both $N$-methyl-d-aspartate (NMDA) and non-NMDA components in all the identified Müller and Mauthner cells examined (Buchanan et al., 1987a). Serotonin reduced the chemical component of Müller EPSPs and did so for all the uniquely identified Müller cells tested (Buchanan and Grillner, 1991).

In summary, while the Müller and Mauthner cells have been the subject of many studies due to their easy access and identifiability, we do not yet understand their role in sensorimotor functions. In addition to the studies described above, studies of regeneration have also exploited their unique identifiability, and these studies are described below in Section 9.

\section{Identified cell classes of the spinal cord}

In contrast to the brainstem, uniquely identifiable neurons have not been described in the lamprey spinal cord. Although the cell bodies of many neurons can be visualized in the relatively transparent spinal cord using transillumination and a stereomicroscope, no distinct pattern of cell bodies is discernable. Without such visual criteria for uniqueness, it remains an open question as to whether identifiable neurons exist in the lamprey spinal cord. Classes of nerve cells, however, can be readily defined and characterized, and studies of these cell classes have contributed significantly to our understanding of spinal circuitry. Many of these studies have focussed on the spinal circuitry underlying locomotor activity. In addition, nerve cell classes have also been of value in examining the specificity of axonal regeneration in the lamprey spinal cord (Section 9). 


\subsection{General properties of lamprey spinal neurons}

Based on the number of regularly occurring ventral and dorsal roots, the spinal cord of the lamprey consists of $\sim 100$ segments, and cell counts indicate that each segment contains 1000 nerve cells (Rovainen, 1979b). Other than the nerve roots, however, there is little apparent segmental organization of the spinal cord. That is, there are no distinctive clusterings or repeating patterns of nerve cells or their processes that would allow one to discriminate segmental boundaries (Rovainen, 1967b, Rovainen, 1974a, Selzer, 1979).

It is possible to recognize several classes of neurons in the spinal cord on the basis of visual cues. These classes include the dorsal cells, lateral interneurons, edge cells, and giant interneurons (each described below). These cells are not arranged in any clearly repeating pattern that might allow recognition of unique individuals, but rather appear randomly distributed within each segment (Selzer, 1979). Similarly, if one examines interneurons labeled with retrograde tracers, no distinctive repeating patterns of cells are apparent (Tang and Selzer, 1979). This lack of repeating patterns is presumably due to variability in cell positions from segment to segment, and this variability prevents the visual recognition of unique individuals, if they exist. Thus, uniquely identifiable spinal neurons have not been demonstrated in the lamprey spinal cord, but classes of spinal neurons can be defined on the basis of morphological and physiological features such as axonal projection, soma size/location, and synaptic sign. The classes of spinal neurons to be considered here (Fig. 2) are motoneurons, lateral interneurons (large inhibitory cells with ipsilateral descending axons), CC interneurons (commissural interneurons), excitatory interneurons (small excitatory cells with ipsilateral axons), inhibitory interneurons (small inhibitory cells with ipsilateral axons), edge cells (intraspinal stretch receptors), giant interneurons (large excitatory cells with ascending contralateral axons), and dorsal cells (primary mechanosensory neurons).

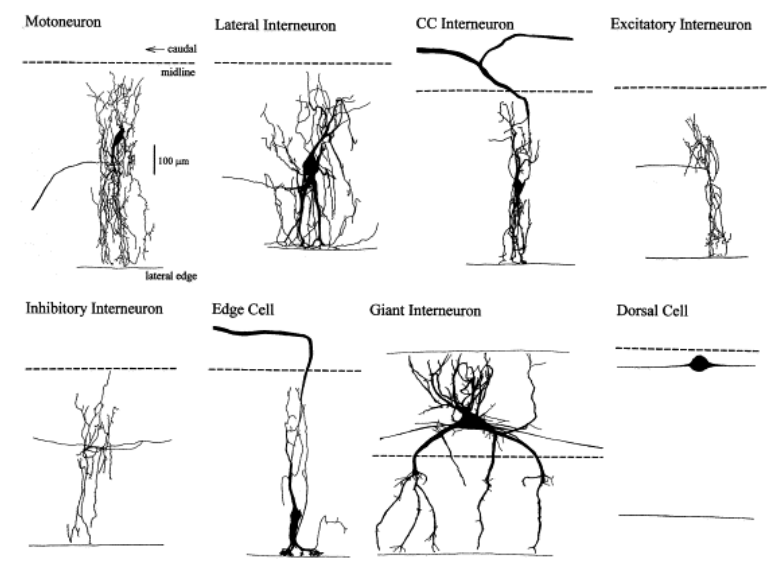

Fig. 2. Drawings of representative cells from identified classes of lamprey spinal neurons. For all drawings, the dashed line represents the midline of the spinal cord, and the lateral edge of the cord is represented by a solid line. Caudal is to the left, and the $100 \mu \mathrm{m}$ calibration bar in the motoneuron drawing applies to all cells. The drawings were made using a drawing tube of cells in wholemount preparations of the spinal cord. The cells were injected intracellularly with either horseradish peroxidase or Lucifer Yellow.

From the representatives in Fig. 2, it is clear that the morphological characteristics of lamprey spinal neurons differ among the cell classes. For example, the sizes of cell bodies can range from $10 \mu \mathrm{m}$ (short axis) for the excitatory and inhibitory interneurons up to $100 \mu \mathrm{m}$ for the giant interneurons. Typically, lamprey spinal neurons have an oval or spindle-shaped cell body with the long axis oriented transversely in the spinal cord with several dendritic branches projecting from the ends of the soma. The dendrites extend out into the axon tracts, often to the margins of the spinal cord, and the degree of dendritic branching differs among the cell classes. The dendrites of most neurons do not cross the midline, although about $10-20 \%$ of motoneurons and CC interneurons do have sparse contralateral dendrites (Wallén et al., 1985, Buchanan, 1982), while the giant 
interneurons always have extensive contralateral dendrites (Rovainen, 1967b). The axons of lamprey neurons tend to have little branching, and they make synaptic contacts en passant as they pass through the dendritic arbors of their postsynaptic targets. Multiple axon collateral branchings, however, are sometimes observed (Buchanan et al., 1989). The number of representatives in each class also differs among classes; 20 giant interneurons per animal (Rovainen, 1967b, Selzer, 1979), 100 lateral interneurons per animal (Selzer, 1979), $\sim 15$ dorsal cells per segment (Rovainen, 1967b, Selzer, 1979), 40 edge cells per segment (Rovainen, 1979b), and $\sim 140$ motoneurons per segment (Rovainen and Dill, 1984). The numbers of cells of other types are less certain. Based on in vitro retrograde labeling using fluorescent dextran amines, there are about 400-600 commissural interneurons per segment and most of these have axons less than 5 segments in length (Ohta et al., 1991).

Based on electrophysiological characteristics, lamprey spinal neurons show many similarities from one class to another. Neurons of all classes characterized thus far are capable of generating action potentials; there have been no reports of non-spiking interneurons in the lamprey spinal cord. In addition, the various cell classes show little or no significant differences in resting potentials or in action potential amplitude and duration, indicating that the basic ionic mechanisms of these processes are similar among the cell classes (Buchanan, 1993). However, significant differences do exist among cell classes in size-related parameters such as input resistance and threshold current for generating action potentials. While all cells can generate a train of action potentials to depolarizing current injections, there are significant differences among the classes with regard to their degree of adaptation, their maximum firing frequencies, and the slopes of their frequency-current plots (even after normalizing to threshold current) (Buchanan, 1993).

\subsection{Motoneurons}

Motoneurons (MN) of the lamprey spinal cord generally have medium-sized cell bodies ( $30 \mu \mathrm{m}$, short axis) and innervate either the muscles of the body wall (Fig. 2) or the muscles of the midline fins. Both types of motoneurons send their axons out nearby ipsilateral ventral roots. Counts of axons in the ventral roots indicate that there are about 140 motoneurons per segment in silver lampreys (Ichthyomyzon unicuspis) and about 200 per segment in sea lampreys (Petromyzon marinus) (Rovainen and Dill, 1984). The motoneurons innervating the muscles of the body wall, the myotomal motoneurons, consist of two types: those that innervate fast, twitchtype muscle fibers and those that innervate slow, non-twitch muscle fibers. The electrophysiological properties of the two types of myotomal motoneurons are similar, although the slow motoneurons tend to have slightly smaller cell bodies and higher input resistances than the fast motoneurons (Teräväinen and Rovainen, 1971). Slow and fast muscle fibers also appear to exist in the fin muscles (Rovainen and Birnberger, 1971). The cell bodies of motoneurons are clearly visible in the spinal cord/notochord preparation but are not recognizable as motoneurons unless pre-labeled with a retrograde tracer. Therefore, they are typically identified electrophysiologically by the one-for-one correspondence of somatic action potentials with spikes recorded extracellularly in the nearby ventral root.

Myotomal and fin motoneurons receive distinctly different patterns of inputs from identified reticulospinal

Müller cells. Generally, the myotomal motoneurons are monosynaptically excited by the ipsilateral $M_{1}, M_{3}, I_{1}, B_{3}$, and $B_{4}$ Müller cells. In contrast, fin motoneurons receive polysynaptic excitation from the contralateral $M_{3}$ and $\mathrm{I}_{1}$ cells (Rovainen, 1974b). Myotomal and fin motoneurons also receive different inputs during fictive swimming. Fin muscle contractions alternate with contractions of the myotomal muscles of the same side, and this alternating pattern is also seen in the membrane potential modulations of the myotomal and fin motoneurons (Buchanan and Cohen, 1982, Shupliakov et al., 1992).

Myotomal motoneurons within the same ipsilateral segment may show significant differences in their morphologies and inputs. Motoneurons that innervate muscle fibers located near the midline of the body, have 
differences in their morphology and fictive swimming inputs compared with motoneurons innervating muscle fibers located in the lateral regions of the body wall. The motoneurons innervating midline muscle fibers tend to have dendrites extending across the midline of the spinal cord whereas those innervating lateral regions of the body wall have only ipsilateral dendrites. Simultaneous intracellular recordings of pairs of motoneurons innervating myotomes at different positions in the body wall showed clear differences in their oscillatory patterns during fictive swimming (Wallén et al., 1985).

\subsection{Lateral interneurons}

Lateral interneurons (LIN) were first characterized by Rovainen (1974a). These are cells with a large soma, prominent lateral dendrites, and an ipsilaterally and caudally projecting axon (Fig. 2). Antidromic axonal stimulations of lateral interneurons located in the rostral spinal cord demonstrated that they can project as far as the tail region of the cord (Rovainen, 1974a). Their large cell bodies ( $45 \mu \mathrm{m}$, short axis) make them clearly visible and recognizable in the rostral half of the isolated spinal cord preparation. In maps of lateral interneurons from stained wholemounts of the spinal cord, Selzer could recognize from 64 to 96 lateral interneurons in different preparations of larval sea lamprey. The variability in their positions from animal to animal precluded identifying unique individual cells (Selzer, 1979).

The most commonly observed synaptic output of lateral interneurons is inhibition of ipsilateral CC interneurons (Buchanan, 1982)(Fig. 3A), and they have also been found to inhibit motoneurons but only rarely (Rovainen, 1982). The lateral interneurons receive direct input from contralateral CC interneurons (Buchanan, 1982) and also from ipsilateral excitatory interneurons (Buchanan and Grillner, 1987), and they receive polysynaptic excitatory and inhibitory inputs from dorsal cells (Rovainen, 1974a). The membrane potentials of lateral interneurons are rhythmically modulated during fictive swimming (Buchanan and Cohen, 1982, Buchanan and Kasicki, 1995), and they have therefore been included in the locomotor network model (Buchanan and Grillner, 1987). Due to their large size, lateral interneurons have been useful for studies of synaptic function. Examples include the characterization of the synaptic transfer function at a Müller axon-to-lateral interneuron synapse (Ringham, 1975, Martin and Ringham, 1975), and the determination of the temperature dependence of the synaptic delay of the chemical component of the Müller-to-lateral interneuron EPSP (Rovainen, 1974b).
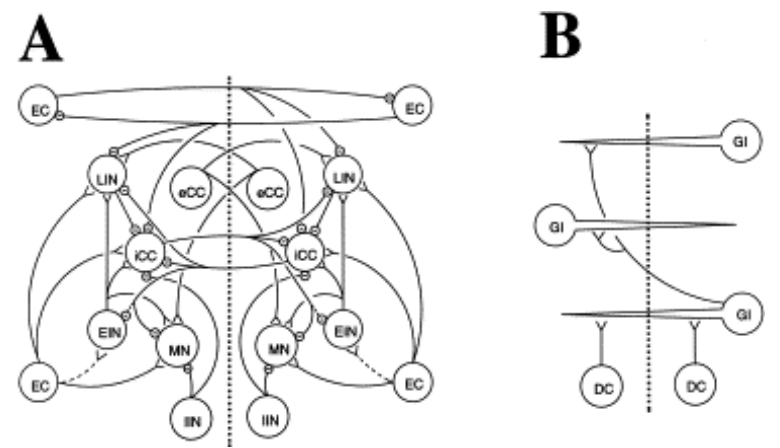

Fig. 3. Synaptic interactions of lamprey spinal neuron classes as determined with paired intracellular microelectrode recordings of membrane potential of pre- and postsynaptic neurons. Thick dashed line represents the midline of the spinal cord. Thin dashed connections represent connections based on indirect evidence but not tested with paired intracellular recordings. Open triangles, excitatory synapses; circles with minus signs, inhibitory synapses; (A) EC, edge cells; LIN, lateral interneurons; eCC, excitatory CC interneurons; iCC, inhibitory CC interneurons; EIN, excitatory interneurons; IIN, inhibitory interneurons. (B) Cells that do not monosynaptically interact with the cells in $A$ are the giant interneurons (GI) and the dorsal cells (DC). 


\subsection{CC interneurons}

'CC interneuron' refers to propriospinal commissural neurons with a main axon branch projecting contralaterally and caudally (Fig. 2). While their small- to medium-sized cell bodies can be visualized in the isolated spinal cord preparation ( $20 \mu \mathrm{m}$, short axis), CC interneurons must be identified by their axonal projection, either electrophysiologically (Buchanan, 1982) or on the basis of retrograde tracers (McPherson and Buchanan, 1995). Intracellular dye injections have revealed that the axons of these cells extend directly towards the midline from the soma or from a dendrite and cross in the ventral commissure. Once on the contralateral side of the cord, the axon turns caudalward as a single axon or bifurcates into both rostral-and caudal-going branches, with the caudal axon having the larger diameter (Buchanan, 1982). The typical axon length of CC interneurons is not known, but based on retrograde labeling, commissural interneurons with shorter axons ( $<5$ segments) are much more numerous than those with longer axons ( $>5$ segments) (Ohta et al., 1991). It is not known whether commissural interneurons with shorter axons are functionally distinct from those with longer axons.

There is substantial morphological diversity among the CC interneurons. Their intracellularly-stained cell bodies ranged from 12 to $35 \mu \mathrm{m}$ in their short axis (mean=20 $\mu \mathrm{m}$ ) (Buchanan 1982), and the input resistances of CC interneurons ranged from 22 to $140 \mathrm{M} \Omega$ (mean=68 $\mathrm{M} \Omega$ ) (Buchanan, 1993). Based upon patterns of inputs from identified reticulospinal Müller cells, at least three subdivisions of CC interneurons were proposed to exist (Buchanan, 1982). One subclass receives excitatory monosynaptic input from only the $B_{1}$ Müller cell of the bulbar Müller group, and these $C C$ interneurons are inhibitory. A second subclass does not receive $B_{1}$ input but is monosynaptically excited by $B_{2-4}$ Müller cells, and these $C C$ interneurons are also inhibitory. The third subclass receives disynaptic inhibition from the ipsilateral $\mathrm{I}_{1}$ Müller cell, and these $\mathrm{CC}$ interneurons are excitatory and typically have sparse contralateral dendrites, in contrast to the exclusively ipsilateral dendrites of the other two classes. The inhibitory CC interneurons are twice as numerous as excitatory CC interneurons based on the frequency of encounter with intracellular microelectrodes (Buchanan, 1982).

The CC interneurons have output synapses on the opposite side of the spinal cord, and their postsynaptic targets include motoneurons, lateral interneurons, and other CC interneurons (Fig. 3A). Single CC interneurons have been shown to interact with all three of these classes of postsynaptic cells (Buchanan, 1982). Indirect evidence indicates that the CC interneurons also inhibit excitatory interneurons (Buchanan et al., 1989). The membrane potentials of CC interneurons are strongly modulated during fictive swimming (Buchanan and Cohen, 1982, Buchanan and Kasicki, 1995), and these cells are thought to play a key role in the generation of fictive swimming (Section 7).

\subsection{Excitatory interneurons}

'Excitatory interneuron' (EIN) refers to a class of small ipsilaterally-projecting neurons that excite nearby motoneurons and interneurons (Fig. 2, Fig. 3A). These cells have been identified electrophysiologically using paired intracellular recordings of presynaptic interneurons and postsynaptic motoneurons and interneurons (Buchanan and Grillner, 1987, Buchanan et al., 1989). Intracellular dye injections revealed that these cells have small cell bodies ( $10 \mu \mathrm{m}$, short axis). The axons of the excitatory interneurons are also small ( $<3 \mu \mathrm{m}$ diameter) and can exhibit multiple branches near the soma with periodic swellings. Electron microscopic examination found that the swellings contain clear spherical synaptic vesicles and make contact with postsynaptic membrane specializations (Buchanan et al., 1989). The axons of excitatory interneurons may project up to 9 segments based on indirect measurements (Dale, 1986), but most appear to be much shorter (Buchanan et al., 1989). The membrane potentials of the excitatory interneurons are strongly modulated during fictive swimming (Buchanan et al., 1989) and thus are thought to provide much of the phasic excitatory drive to motoneurons and interneurons during swimming. 
The excitatory interneurons are probably quite numerous because in spite of their small size, they are encountered frequently with random microelectrode impalements of neurons in the gray area of the spinal cord ( $\sim \%$ of impalements). The excitatory interneurons are a morphologically diverse group, and may therefore also be functionally diverse. Wide ranges of soma sizes, 8-18 $\mu \mathrm{m}$ (short axis) (Buchanan et al., 1989), and input resistances, 12-220 $\mathrm{M} \Omega$ (mean=72 $\mathrm{M} \Omega$ ) (Buchanan, 1993), have been found for these cells. The axons of the excitatory interneurons may project either caudally or rostrally, or may bifurcate and project in both directions. Due to the difficulty in obtaining quality impalements for long periods, relatively little is known about the synaptic interactions of these cells compared with other cell types. It is known that motoneurons are not their only postsynaptic target because the excitatory interneurons can also excite lateral interneurons and CC interneurons (Buchanan and Grillner, 1987), and indirect evidence indicates that they also excite other excitatory interneurons (Buchanan et al., 1989). Although they receive reticulospinal inputs, the pattern of inputs from identified Müller cells has not been established (Buchanan and Grillner, 1987).

\subsection{Inhibitory interneurons}

'Inhibitory interneuron' (IIN) refers to small interneurons that are similar in morphology to the excitatory interneurons, but they produce IPSPs in nearby ipsilateral motoneurons, rather than EPSPs (Fig. 2) (Buchanan and Grillner, 1988). These cells appear to be much less common than the excitatory interneurons because they are encountered less frequently during random microelectrode impalements while using motoneurons as the postsynaptic target ( $1 \%$ of impalements) (Buchanan et al., 1989). The inhibitory interneurons also inhibit nearby CC interneurons, and they are modulated in phase with nearby motoneurons during fictive swimming (Buchanan and Grillner, 1988). Due to the rarity of encountering these small inhibitory interneurons, little is known about them. It is possible that the inhibitory interneurons are actually quite numerous, but that motoneurons are not their primary target. By analogy with the large lateral interneurons, which also produce ipsilateral inhibition, the small local inhibitory interneurons may have CC interneurons as their primary postsynaptic target, rather than motoneurons. This hypothesis could be tested by using CC interneurons as the postsynaptic cell when searching for local inhibitory interneurons.

\subsection{Edge cells}

The edge cells are intraspinal-stretch-receptors, that are also propriospinal interneurons (Fig. 2). Edge cells are medium- to large-sized neurons (soma size of 20-50 $\mu \mathrm{m}$, short axis) located in the lateral axon tracts of the spinal cord (Rovainen, 1974a), and number $\sim 40$ per segment (Rovainen, 1979b). They have a characteristic fine dendritic tuft at the lateral edge of the cord (Wallén et al., 1988) which presumably mediates stretch transduction. The edge cells are equally divided between those with a contralateral axon projection and those with an ipsilateral axon projection. The axon projections of both types of edge cells are mainly in the rostral direction and only over a few segments (Rovainen, 1974a, Tang and Selzer, 1979). Contralaterally-projecting edge cells are inhibitory and have been shown to inhibit other edge cells, lateral interneurons, and CC interneurons (Rovainen, 1974a, Viana Di Prisco et al., 1990). Ipsilaterally projecting edge cells are excitatory and have been shown to excite motoneurons and CC interneurons (Viana Di Prisco et al., 1990) (Fig. 3A). In the region of the dendritic tufts at the lateral edge of the cord, there are many small processes that are immunoreactive for a variety of neuropeptides (Buchanan et al., 1987b). Prominent are the processes with somatostatin-like immunoreactivity, which originate from cell bodies near the central canal and which also contain GABA immunoreactivity. Both GABA and somatostatin have been shown to hyperpolarize edge cells, but by different ionic mechanisms (Christenson et al., 1991).

The first evidence that intraspinal stretch receptors exist in lamprey was that rhythmic lateral bending of the isolated spinal cord can entrain the fictive swim burst rate, (Grillner et al., 1982, McClellan and Sigvardt, 1988, Williams et al., 1990). Intracellular recordings from edge cells while applying small stretches to the spinal cord demonstrated that edge cells depolarize in response to stretch, supporting the conclusion that they are 
intraspinal stretch receptors (Grillner et al., 1984). During fictive swimming, the membrane potentials of edge cells are only weakly modulated (Buchanan and Cohen, 1982, Buchanan and Kasicki, 1995, Vinay et al., 1996). Edge cells receive tonic bicuculline-sensitive IPSPs during fictive swimming that may obscure phasic strychninesensitive IPSPs (Alford et al., 1990).

\subsection{Giant interneurons}

Due to their large soma sizes (up to $100 \mu \mathrm{m}$ ), giant interneurons are clearly visible in the caudal half of the isolated spinal cord/notochord preparation. The number of giant interneurons averages only about 20 per animal (Rovainen, 1967b), but maps of their locations in different animals show a degree of variability that prevents them from being uniquely identifiable (Selzer, 1979). Each giant interneuron has a contralaterally and rostrally projecting axon that can reach the rostral spinal cord or brainstem (Rovainen, 1967b, Rovainen et al., 1973). The dendrites of giant interneurons extend prominently across the midline of the cord (Fig. 2). Giant interneurons are not the only spinal neurons with contralaterally and rostrally projecting axons (Tang and Selzer, 1979), and it is not yet clear whether smaller versions of giant interneurons with similar function also exist.

Giant interneurons make excitatory electrical/chemical synaptic connections upon more rostrally-located giant interneurons, and these postsynaptic cells can be located either ipsilaterally or contralaterally to the presynaptic cell (Rovainen, 1974a) (Fig. 3B). Giant interneurons have also been shown to produce EPSPs on the identified Müller cell $B_{3}$ (Rovainen, 1974b). In addition to inputs from other giant interneurons, they can be excited by mechanical stimulation of the fin and body skin (Teräväinen and Rovainen, 1971), and they receive monosynaptic and polysynaptic excitatory inputs from dorsal cells (Rovainen, 1974b). Giant interneurons rarely synapse upon other identified classes of spinal neurons (Rovainen, 1974a), and they show little or no rhythmic activity during fictive swimming (Buchanan and Cohen, 1982). On the basis of their direct dorsal cell input and their ascending axons that can reach the brainstem, the giant interneurons have been considered to be secondorder sensory relay neurons (Rovainen, 1974a).

Giant interneurons have been the subject of numerous studies due to their ease of identification and microelectrode impalement. For example, Christensen used electrophysiological and electron microscopic measurements to construct Rall models of the giant interneurons to compare the physical and electrotonic distances of synapses formed by the bursting axon, $I_{2}$ (Section 3) (Christensen, 1983). Giant interneurons have also been used in studies examining the actions of various neurotransmitters (e.g. Martin et al., 1970, Homma and Rovainen, 1978, Homma, 1979, Homma, 1985) and other pharmacological agents (Selzer, 1978, Hill et al., 1985). They have also proven useful for studies of regeneration of synaptic connections after spinal transection (Section 9).

\subsection{Dorsal cells}

The dorsal cells are primary mechanosensory neurons located in the dorsomedial region of the spinal cord, and they correspond to the Rohon-Beard cells of larval teleosts and amphibians (Clarke et al., 1984, Nakao and Ishizawa, 1987). The dorsal cells are typically bipolar with ascending and descending processes in the dorsal columns (Fig. 2). The peripheral process of each dorsal cell innervates the skin and enters the spinal cord via a dorsal root. The cell bodies are $\sim 40 \mu \mathrm{m}$ in diameter and number $\sim 15$ per segment (Rovainen, 1967b, Selzer, 1979). The dorsal cells respond to touch of the skin, and they were initially classified into three types on the basis of force threshold: touch, pressure, and nociceptive (Martin and Wickelgren, 1971). A later study confirmed the existence of the touch and pressure dorsal cells, but found no evidence for nociceptive dorsal cells (Christenson et al., 1988a). Touch and pressure cells can be distinguished electrophysiologically by their latency to spike initiation during rebound from a hyperpolarizing current pulse: touch cells spike in $<11 \mathrm{ms,}$ pressure cells spike in >11 ms (Christenson et al., 1988a). This difference appears to be due to low-voltage 
activated calcium channels present in the touch cells, but not present in the pressure cells (Christenson et al., 1993).

Synaptic potentials are only rarely observed in dorsal cells (Rovainen, 1967b), and ultrastructurally, presynaptic profiles are sparse on the cell bodies (Christenson et al., 1988b). Correspondingly, their cell bodies are generally unresponsive to neurotransmitters, but GABA can broaden calcium spikes induced pharmacologically, and this broadening appears to be due to reduction of an calcium-activated potassium current in these cells. This action of GABA is mimicked by forskolin, indicating involvement of cAMP (Leonard and Wickelgren, 1986, Womble and Wickelgren, 1990). Substance $P$ also broadens the action potential of dorsal cells and reduces the afterhyperpolarization following the action potential. These actions of substance $P$ are mediated by protein kinase $\mathrm{C}$ and involve the reduction of a 4-aminopyridine-sensitive potassium current (Parker and Grillner, 1996, Parker et al., 1997).

Dorsal cells have been shown to produce monosynaptic EPSPs in giant interneurons, and polysynaptic EPSPS and IPSPs in motoneurons, lateral interneurons, edge cells, and CC interneurons (Rovainen, 1974b, Buchanan, 1982). The monosynaptic EPSPs from dorsal cells to giant interneurons have been exploited in studies of presynaptic neuromodulation by serotonin (el Manira et al., 1997) and substance P (Parker and Grillner, 1996). Dorsal cells participate in local reflexes (Teräväinen and Rovainen, 1971), and they can have powerful effects on fictive swimming when electrically stimulated, but their membrane potentials show little or no modulation during fictive swimming (Buchanan and Cohen, 1982, Buchanan and Kasicki, 1995, el Manira et al., 1996).

Dorsal cells are easily recognized after dissociation from the spinal cord and have been used for whole-cell patch clamp studies. Calcium currents in isolated dorsal cells have been characterized and shown to consist of both low- and high-voltage calcium channels (el Manira and Bussières, 1997), and these calcium currents are reduced by $\mathrm{GABA}_{B}$ agonists (Batueva et al., 1999).

\section{Synaptic interactions among spinal neurons}

The ability to readily identify classes of spinal neurons has allowed mapping of synaptic interactions among these cells. A summary of most of the known monosynaptic interactions among the characterized classes of spinal neurons in the lamprey is shown in Fig. 3. These synaptic interactions have been demonstrated using simultaneous intracellular recordings of the pre- and postsynaptic neurons (Rovainen, 1967b, Rovainen, 1974a, Buchanan, 1982, Buchanan and Grillner, 1987, Buchanan and Grillner, 1988, Buchanan et al., 1989, Viana Di Prisco et al., 1990). Postsynaptic potentials are considered to be monosynaptic if they follow stimulation of the presynaptic cell at frequencies of $10 \mathrm{spikes} / \mathrm{sec}$ with constant latency and with synaptic delays near $2 \mathrm{~ms}$ at $\sim 8^{\circ} \mathrm{C}$. It must be emphasized that these illustrated interactions do not exist between all pairs of cells in the cell classes, but rather in only about $10-15 \%$ of cell pairs. It may be that these low contact frequencies reflect in part the inability to uniquely identify the cells or to recognize possible diverse subclasses of cells.

The connectivity diagram of Fig. 3A shows no feedback connections from motoneurons. In the embryonic Xenopus spinal cord, Perrins and Roberts (1995a) and Perrins and Roberts (1995b) have demonstrated excitatory connections from spinal motoneurons to other motoneurons and interneurons, and they consider the motoneurons to be part of the rhythm-generating network. In early studies in lamprey, antidromic firing of motoneurons by electrically stimulating ventral roots did not reveal recurrent inhibition (Teräväinen and Rovainen, 1971, Rovainen and Birnberger, 1971) nor did antidromic stimulation alter fictive swimming in adjacent ventral roots (Wallén and Lansner, 1984). On the basis of these experiments, the motoneurons have been considered to be passive output elements, but recent experiments contradict this view by demonstrating feedback connections from motoneurons to the locomotor network (Buchanan et al., 1998). 


\section{Pharmacology of synaptic potentials}

During simultaneous intracellular recordings of pre- and postsynaptic neurons, the pharmacology of many of the monosynaptic PSPs of Fig. 3 have been tested by application of selective neurotransmitter antagonists. The IPSPs in the spinal cord of the lamprey have been shown to be chloride-dependent, and all monosynaptic IPSPS tested with paired recordings have been reduced by strychnine, indicating that they are glycinergic. These IPSPs include the output synapses of the following cells: CC interneurons, lateral interneurons (McPherson et al., 1994), local inhibitory interneurons (Buchanan and Grillner, 1988), and edge cells (Viana Di Prisco et al., 1990). There are also cells within the lamprey spinal cord that show GABA-like immunoreactivity (Batueva et al., 1990, Brodin et al., 1990), and it has been shown that rhythmic subthreshold modulations of axonal membrane potentials during fictive swimming are reduced by $\mathrm{GABA}_{A}$ and $G A B A_{B}$ receptor antagonists (Alford et al., 1991), but no intracellular recordings have yet been made from GABAergic neurons.

All chemical EPSPs tested thus far in the lamprey have been shown to be reduced by antagonists of excitatory amino acids. The output synapses of the following cells have been tested: excitatory interneurons (Buchanan and Grillner, 1987, Buchanan et al., 1989), reticulospinal cells (Buchanan et al., 1987a, Ohta and Grillner, 1989), edge cells (Viana Di Prisco et al., 1990), and dorsal cells (Brodin et al., 1987). The reticulospinal EPSPs in motoneurons have both NMDA and non-NMDA components (Buchanan et al., 1987a, Ohta and Grillner, 1989), while the edge cell EPSPs in unidentified neurons are completely blocked by non-NMDA antagonists (Viana Di Prisco et al., 1990) as are the EPSPs produced by dorsal cells in giant interneurons (Brodin et al., 1987, Christenson and Grillner, 1991).

\section{Roles of spinal neurons in swimming}

A major contribution of the study of nerve cell classes in the lamprey spinal cord has been to advance our knowledge of the cellular basis for locomotor activity. While it is clear that our understanding is far from complete, progress has been made in identifying which cell types are involved and how their synaptic interactions may contribute to the generation of the locomotor rhythm.

\subsection{Characteristics of fictive swimming}

The in vitro lamprey spinal cord preparation shows little spontaneous activity in the absence of electrical or chemical stimulation. However, Poon (1980) discovered that when a spinal cord/notochord preparation with some myotomal muscles left in place was superfused with an excitatory amino acid such as glutamate, rhythmic movements resembling swimming were evoked. It was then shown by Cohen and Wallén (1980) that this swimming activity was due to a central pattern generator because it was also present in the spinal cord/notochord preparation without muscle tissue or movement and recorded as ventral root discharges. This rhythmic activity is similar to the pattern of electromyographic activity recorded in intact lampreys and is thus referred to as fictive swimming (Wallén and Williams, 1984).

The motor pattern of lamprey swimming consists of lateral undulations of the body which propagate from the head towards the tail. In the spinal cord/notochord preparation, the corresponding pattern consists of rhythmic bursts of action potentials in ventral roots which alternate between the two sides of the spinal cord, and the burst onset of each ventral root leads the burst onset in the next caudal ventral root of the same side (Fig. 4). Both the durations of the action potential bursts and the delays of the burst onsets along the cord are scaled to cycle period so that for a wide range of cycle periods, the burst durations remain constant at about 35-40\% of the cycle period, and the onset delays remain constant at about $1 \%$ of the cycle period per segment (Wallén and Williams, 1984). This $1 \%$ phase lag per segment over a body of $\sim 100$ segments means that the lamprey maintains about one swim cycle per body length during a wide range of swimming speeds. Since fictive swimming can be elicited in as few as 2-3 segments taken from any level of the spinal cord, the spinal cord is 
considered to contain a chain of overlapping, coupled oscillators. Each unit oscillator (1-3 segments) produces the basic alternating activity, and the coupling among oscillators produces the rostral-to-caudal propagation of the activity (Cohen et al., 1992).

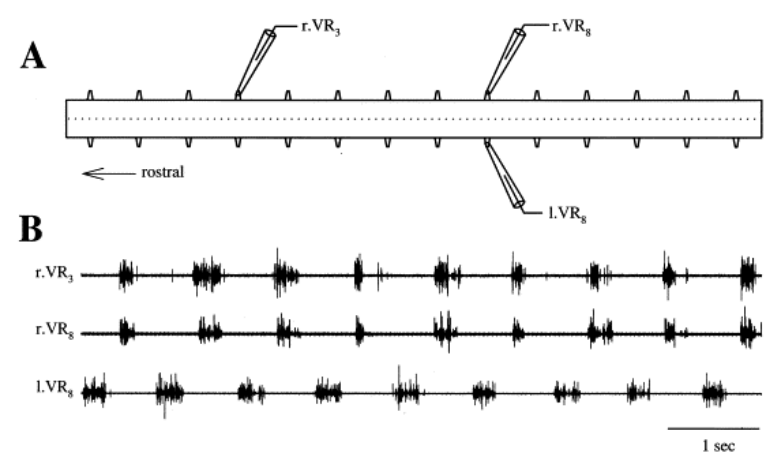

Fig. 4. Fictive swimming in the lamprey spinal cord/notochord preparation. (A) A 12-segment length of spinal cord was exposed to $0.15 \mathrm{mM}$ NMDA and three ventral roots (VR) were recorded with suction electrodes. (B) Rhythmic bursting from the ventral roots alternate from side to side, and ventral roots on the same side are nearly synchronous but caudal roots lag more rostral roots by about $1 \%$ of a cycle period per segment.

Fictive swimming can also be induced in the brainstem/spinal cord preparation without the addition of an exogenous excitatory amino acid. In this preparation in which the brainstem is left attached to the spinal cord, bouts of fictive swimming sometimes occur spontaneously or can be elicited by brief electrical stimulation of brainstem sites, of the cranial nerves, or of the spinal cord (McClellan and Grillner, 1984, Kasicki and Grillner, 1986). In the absence of the brainstem, brief bouts of fictive swimming can also be induced in the spinal cord without exogenous excitatory amino acid by stimulating tail skin left innervated by the spinal cord (McClellan and Grillner, 1983).

\subsection{Neuronal activity during fictive swimming}

Intracellular microelectrode recordings of membrane potential have been made from representatives of various spinal neuron classes during fictive swimming. Similar results have been obtained both in the isolated spinal cord/notochord preparation with an excitatory amino acid added to induce swimming activity (Buchanan and Cohen 1982) and in the brainstem/spinal cord preparation without adding an excitatory amino acid (Fig. 5)(Buchanan and Kasicki 1995). During fictive swimming, oscillating membrane potentials are robust (5-15 mV, trough to peak) in motoneurons, lateral interneurons, CC interneurons, excitatory interneurons, and inhibitory interneurons, but are weak or absent in edge cells, giant interneurons, and dorsal cells (Buchanan, 1982, Buchanan and Cohen, 1982, Kahn, 1982, Russell and Wallén, 1983, Buchanan and Grillner, 1988, Buchanan et al., 1989, Buchanan and Kasicki, 1995, el Manira et al., 1996, Vinay et al., 1996). The oscillations consist of excitatory depolarizing phases alternating with chloride-dependent inhibitory repolarizing phases, as shown by chloride injections into motoneurons (Russell and Wallén, 1983), lateral interneurons, CC interneurons (Kahn, 1982), and excitatory interneurons (Buchanan et al., 1989). The peaks of the depolarizations tend to occur near the midpoints of the ventral root bursts except for the CC interneurons. The depolarizing peaks in CC interneurons occur significantly earlier, near the beginning of the ventral root bursts (Fig. 5D). For all the cells, the alternating excitatory and inhibitory phases are due to the summations of EPSPs and IPSPs, respectively. These PSPs presumably originate from the convergence of many presynaptic neurons because interneurons active in fictive swimming usually fire only a few spikes (0-2) during each swim cycle (Fig. $5 \mathrm{C}$ ), and the individual PSPs are small (typically $\sim 0.5 \mathrm{mV}$ ). 

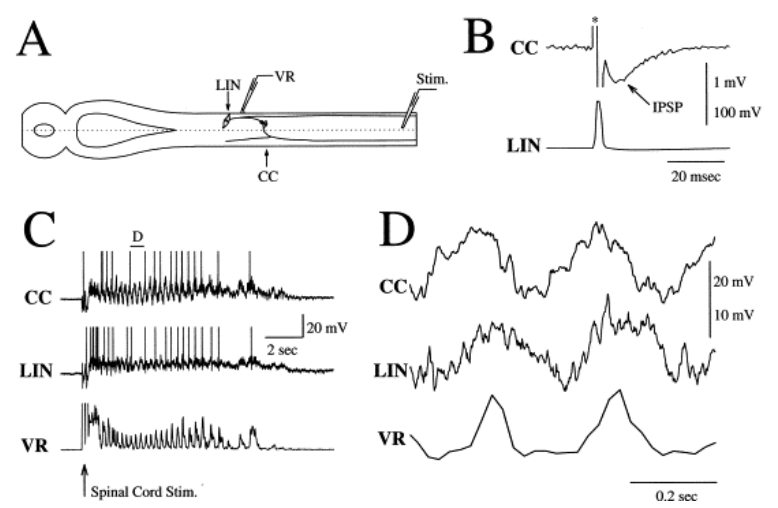

Fig. 5. Representative neuronal activity occurring during fictive swimming in a brainstem/spinal cord preparation. (A) Schematic representation of a brainstem/spinal cord preparation with paired intracellular recording from a lateral interneuron (LIN) and a CC interneuron and an extracellular recording of the nearby ventral root (VR). Electrical stimulation (Stim) of the dorsal columns was used to initiate bouts of swimming activity. (B) The IPSP produced in a CC interneuron by a lateral interneuron located one segment rostral and ipsilateral to the $\mathrm{CC}$ interneuron as illustrated in A. The asterisk indicates the stimulus artifact produced by current injection into the lateral interneuron. (C) The activities of the same two interneurons of B during a bout of swim activity induced by a brief electrical stimulation to the spinal cord. The rectified and filtered activity of the nearby ipsilateral ventral root (VR) is also shown. Action potentials are truncated. (D) Expansion of the indicated region in $\mathrm{C}$ showing that the membrane potential oscillations of the CC interneuron are slightly phase advanced of the lateral interneuron and the ventral root. The convergence of input from several lateral interneurons may be responsible for the early fall of membrane potential in CC interneurons during fictive swimming compared with other ipsilateral cell types.

An additional factor contributing to the shaping and the amplitude of the oscillations in some neurons may be tetrodotoxin-resistant membrane potential oscillations induced by activation of $\mathrm{N}$-methyl-d-aspartate (NMDA) receptors (Grillner and Wallén, 1985, Sigvardt et al., 1985, Wallén and Grillner, 1985, Wallén and Grillner, 1987, Brodin et al., 1991, Murphey et al., 1995). Since these oscillations are observed in the presence of tetrodotoxin, they are not due to spike-mediated synaptic transmission, and they do not appear to depend upon graded synaptic transmission because the frequency of the oscillations in a single cell can be easily manipulated by changing the cell's membrane potential with current injections. These NMDA oscillations may amplify the actions of EPSPs and IPSPs during the swim cycle (Wallén and Grillner, 1985, Wallén and Grillner, 1987). The NMDA oscillations have been observed in motoneurons and CC interneurons but not in lateral interneurons, edge cells, or dorsal cells (Wallén and Grillner, 1987).

\subsection{The locomotor network and modeling}

A subset of the network of Fig. 3A has been proposed to be the basis of a unit oscillator for the locomotor network and consists of three classes of interneurons: inhibitory CC interneurons, lateral interneurons, and excitatory interneurons (Buchanan, 1986, Buchanan and Grillner, 1987). This network (Fig. 6A) has similarities with the spinal networks found in the embryonic Xenopus spinal cord (Roberts, 1990) and in the adult goldfish (Fetcho, 1990). In particular, inhibitory commissural interneurons and descending excitatory interneurons are common to all three networks. The main difference in the networks is that no cell type analogous to the lateral interneurons has been identified in Xenopus or in the goldfish. A second difference is that the motoneurons of the lamprey have been considered to be only passive output elements, whereas in Xenopus, the motoneurons have been shown to synaptically interact with spinal interneurons and may participate in locomotor rhythmogenesis (Perrins and Roberts, 1995b). As noted above (Section 5), this view in lamprey may require revision (Buchanan et al., 1998). 


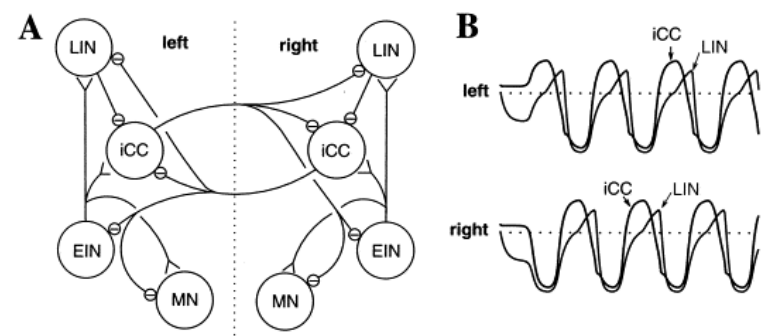

Fig. 6. Proposed model for the locomotor network. (A) A subset of the cells and synaptic interactions of Fig. 3A proposed to be the core rhythm-generating network for locomotion in lamprey. (B) Connectionist-style simulation of the network of $A$ shows that the activities (i.e. membrane potential) of the cells are rhythmic and that cells on opposite sides alternate in their activity. In addition, the CC interneurons are slightly phase advanced in relation to the lateral interneurons. The lateral interneurons are co-active with the excitatory interneurons and motoneurons of the same side. The phase advance of the inhibitory CC interneurons is due to the feedforward inhibition of CC interneurons from ipsilateral lateral interneurons and is important in the generation of rhythmic activity by preventing the CC interneuron activity from locking on one side. MN, motoneurons; LIN, lateral interneurons; iCC, inhibitory CC interneurons; EIN, excitatory interneurons.

Not included in the proposed network of Fig. 6A are excitatory CC interneurons, edge cells, and local inhibitory interneurons. The excitatory CC interneurons and edge cells are omitted because they are only weakly active during fictive swimming (Buchanan and Cohen, 1982), and the inhibitory interneurons are omitted because these cells are only rarely encountered and are poorly characterized (Buchanan and Grillner, 1988).

For producing rhythmic alternating activity, the core of the proposed network is the reciprocal inhibition between CC interneurons on opposite sides of the spinal cord. A second important feature for rhythm generation is the feedforward inhibition to ipsilateral CC interneurons from lateral interneurons (see Fig. 5B), which can account for the phase advance of the membrane potential oscillations of CC interneurons and provides a mechanism for limiting the duration of CC interneuron activity, and thus preventing locking of activity on one side of the network. During a swim cycle, CC interneurons and lateral interneurons of one side of the cord reach threshold, and the firing CC interneurons then inhibit cells on the opposite side of the spinal cord, promoting further firing of the active side by removing inhibition coming from the contralateral CC interneurons. The active lateral interneurons, however, begin to inhibit the ipsilateral CC interneurons and eventually terminate their firing. This releases the cells of the opposite side from inhibition, and under a depolarizing drive, the released CC interneurons depolarize towards threshold, spike, and then inhibit cells on the formerly active side of the cord, and the sequence as described repeats on the newly active side. In the spinal cord/notochord preparation, the depolarizing drive comes in part from an exogenously-applied excitatory amino acid, and may also come from mutual excitation among the excitatory interneurons since there is evidence that excitatory interneurons excite other excitatory interneurons (Buchanan et al., 1989). In the brainstem/spinal cord preparation, excitatory reticulospinal cells are active during fictive swimming and thus contribute to the depolarizing drive to spinal neurons (Kasicki and Grillner, 1986, Kasicki et al., 1989).

That the network of Fig. $6 \mathrm{~A}$ can indeed function in the fashion described above to generate rhythmic activity resembling the locomotor pattern in the lamprey has been confirmed with computer simulations of mathematical models of the network. Two styles of computer simulations have been used: connectionist models (Buchanan, 1992, Williams, 1992) and more detailed biophysical models (Grillner et al., 1988, Ekeberg et al., 1991, Wallén et al., 1992). In the connectionist-style simulations, the cells are represented as simple neural units with sigmoidal input/output functions and lacking action potentials and electrotonic structure. When the synaptic connectivity of Fig. 6A is imposed, the network can produce rhythmic activity that alternates between the two sides (Fig. 6B), as does the lamprey locomotor rhythm (Fig. 4). Further similarity between model and 
lamprey is found in the phase relations of cells on the same side. In both the model and the lamprey, all of the cells on the same side are co-active except the CC interneurons which are slightly phase advanced with respect to the other cells (compare Fig. 5DFig. 6B). In addition, these unit oscillatory networks can be interconnected in chains using the cells of the network as the inter-oscillator coupling signals to produce a rostral-to-caudal propagation of activity mimicking the constant phase lag of lamprey swimming (Buchanan, 1992, Williams, 1992). In the more detailed biophysical models of the proposed locomotor network, each neuron is represented with an electrotonic structure and with both voltage- and ligand-gated channels modeled with Hodgkin-Huxley formalism. These more elaborate simulations also exhibit alternating rhythmic activity when connected according to the circuit of Fig. 6A (Grillner et al., 1988, Ekeberg et al., 1991, Wallén et al., 1992). While the biophysical parameters for the various channels have not been measured in lamprey neurons and are therefore only estimates that reproduce overall cell properties, these biophysically-detailed models will ultimately be valuable for assessing the roles of specific ionic currents in network behavior.

Computer simulations show the basic feasibility of the proposed network. Since the network is based upon classes of characterized neurons and their demonstrated synaptic interactions, it is possible to design experiments to test the network. Described below are pharmacological and lesion experiments that attempt to determine whether commissural interneurons are necessary for rhythm generation. More subtle pharmacological manipulations using neuromodulators are discussed in a separate section (Section 8).

\subsection{Experimental tests of the model}

\subsubsection{Strychnine}

The proposed network of Fig. 6A predicts that if the reciprocal inhibition between CC interneurons is eliminated, rhythmicity in the lamprey spinal cord will also be eliminated. Since it has been shown that the IPSPs produced by CC interneurons are blocked by strychnine, one experimental strategy for eliminating reciprocal inhibition is to apply strychnine during fictive swimming. In a model relying on reciprocal inhibition, it would be expected that as the IPSPs of reciprocal inhibition are weakened, the burst rate will increase. Strychnine, however, also blocks the IPSPs produced by lateral interneurons upon CC interneurons, and this complicates the interpretation of the experiment because the lateral interneuron feedforward inhibition of CC interneurons also plays a role in rhythm generation in the model. The model predicts that weakening only the output IPSPs of lateral interneurons will slow the oscillations (Buchanan, 1992). Strychnine application would therefore have opposing effects on the cycle period of the network by acting at both sets of synaptic connections. Nonetheless, with complete block of IPSPs, the rhythm should be abolished.

In the lamprey, application of strychnine has complicated effects on the fictive swim rate. Initially, the rate speeds and then can breakdown entirely (Grillner and Wallén, 1980, McPherson et al., 1994). Also, a slow rhythm can develop which appears to be due to a slow modulation (period $\sim 20 \mathrm{~s}$ ) superimposed on the fast rhythm (McPherson et al., 1994). It is also possible to observe a rapid bursting which is synchronized between the two sides of the cord (Cohen and Harris-Warrick, 1984). In the latter case, the synchrony between the two sides could be produced by excitatory CC interneurons, and the oscillatory activity could be due to seizure-like synchronization of cell activity. Thus, the actions of strychnine on fictive swimming are not easily interpretable according to the proposed network model.

\subsubsection{Lesions}

Another approach to eliminating reciprocal inhibition between CC interneurons on opposite sides of the cord is to sever the axons of commissural interneurons at the midline. Longitudinal midline cuts can be made easily in the spinal cord/notochord preparation due to the flattened shape of the spinal cord and the clear visibility of the midline. Cuts extending only a few segments have little effect on the fictive swimming rhythm while longer cuts are disruptive. If the midline cut is made from either end of a spinal cord piece and extends only partially along 
the cord, then the farther a spinal segment in the split cord is located from intact spinal cord, the less regular is its rhythmic ventral root bursting. If the cut is complete so that the left and right sides are completely separated, the swim rhythm is abolished (Fig. 7A), as predicted by the model. The remaining ventral root activity is continuous although occasional periods of high-frequency bursting can sometimes be detected (Buchanan, 1999). These experiments provide evidence that the commissural interneurons are critical for rhythm generation.
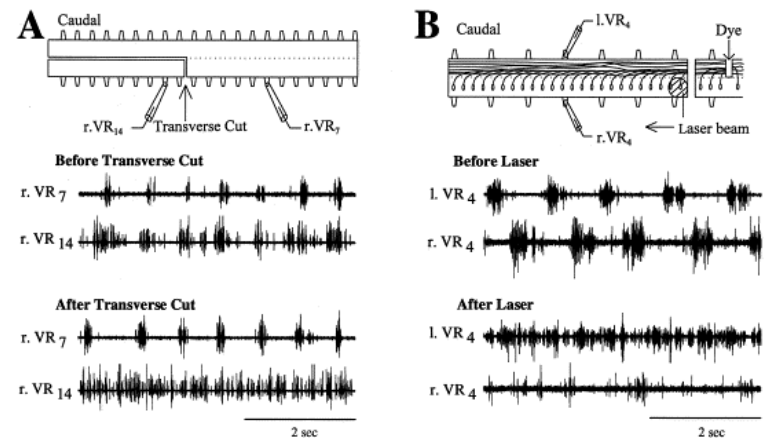

Fig. 7. Two types of experimental evidences that commissural interneurons are necessary for rhythmogenesis in the lamprey spinal cord. (A) In the first type of experiment, a midline cut to sever axons of commissural interneurons was made from the caudal end of a spinal cord/notochord preparation. Before transverse cut, the split cord (r.VR14) still showed rhythmic bursting related to fictive swimming in the intact cord (r.VR7). After transverse cut, the indicated transverse cut isolated the right side of the split cord from intact cord and regular rhythmic bursting was lost. (B) In a second type of experiment, retrogradely-labeled commissural interneurons were photo-inactivated during fictive swimming. The commissural interneurons of one side of the cord were retrogradely labeled with eosin- and fluorescein-dextran amines. Before Laser, the fictive swim activity recorded in ventral roots on opposite sides was normal. After Laser, illumination of the entire 7-segment length of spinal cord by slowly moving the beam of an argon laser along the side of the cord containing the retrogradely-labeled commissural cells resulted in a disruption of rhythmic activity.

An alternative to cutting the axons of commissural interneurons is to inactivate the commissural cells using photo-toxic dyes. This technique has been used in the stomatogastric ganglion of the lobster to determine the effects of removing single identified neurons from the rhythm-generating network. In the stomatogastric preparation, single cells were injected with Lucifer Yellow and then inactivated by illuminating the ganglion with an intense blue light (Miller and Selverston, 1979, Selverston and Miller, 1982). In lamprey, elimination of single neurons is not likely to affect rhythm generation due to the large numbers of participating cells. However, by using retrograde labeling of commissural interneurons with photo-toxic dyes, it is possible to inactivate large populations of commissural interneurons.

For these experiments, commissural interneurons are retrogradely labeled with a mixture of eosin dextran amines and fluorescein dextran amines by applying the dyes to a transverse cut made on one side of the spinal cord. Eosin is used because it is known to be highly photo-toxic (Spikes, 1991), and the fluorescein allows for visualization of the cells in the in vitro preparation (McPherson and Buchanan, 1995). One week after dye application, there is labeling of cell bodies and axons ipsilateral to the dye application site and labeling of the cell bodies of commissural interneurons on the contralateral side (Fig. 7B). Cells containing the retrograde label exhibit normal electrophysiological properties in the absence of illumination, but illumination with the beam of an argon laser depolarizes the cells within minutes, broadens their action potentials, and blocks action potential conduction along their axons. Unlabeled cells in the same segments containing labeled cells are not affected by the illumination (Buchanan and McPherson, 1995). 
By illuminating only the side of the cord containing the retrogradely-labeled cell bodies of commissural interneurons, it is thus possible to inactivate these cells selectively during fictive swimming. The circular beam of an argon laser is adjusted to be slightly less than one half the width of the spinal cord and is then moved slowly along the cord ( $~ 8 \mathrm{~min}$ per segment) (Fig. 7B). The typical effect of the illumination is to alter the symmetry of ventral root burst durations: the bursts of the illuminated side become shorter while the bursts of the nonilluminated side become longer. In addition, the rate of fictive swimming becomes less regular and in extreme cases, rhythmic activity is abolished (Fig. 7B). The effects are consistent with the model of Fig. 6A. As the inhibitory CC interneurons of the illuminated side are inactivated, their periodic inhibition of neurons on the non-illuminated side becomes weaker and thus bursts on the non-illuminaed side become longer. The CC interneurons of the non-illuminated side will in turn inhibit the motoneurons of the illuminated side for a longer time and thus shorten the burst durations on the illuminated side. In the extreme, the rhythm is lost as the illuminated CC interneurons become completely inactivated. Control experiments using the same illumination during fictive swimming without prior retrograde labeling have no effects on the swim rhythm (Buchanan and McPherson, 1995).

\subsection{Swim network summary}

Thus, the lesion experiments support the idea that commissural interneurons play a key role in rhythmogenesis, and computer simulations demonstrate the feasibility of the proposed locomotor network. However, it has not yet been possible to selectively test the roles of other cell types such as the lateral interneurons. With regard to coupling, computer simulations can demonstrate the feasibility of various schemes for coupling the unit oscillators to yield realistic phase lags, however, little is known about the identities of the actual coupling signals. Considering the large numbers of cells in each spinal segment and the relatively few studies devoted to characterizing cell types in the lamprey, much more clearly remains to be learned regarding neuron classes and their roles in locomotor activity.

\section{Neuromodulation of swimming activity}

Invertebrate preparations have clearly demonstrated the utility of using identified neurons for understanding the actions of neuromodulators on network function (Harris-Warrick and Marder, 1991). These studies have led to the view that neuronal networks are not hard-wired, static circuits, but are subject to modulatory influences by various neurotransmitters and neuropeptides, which act by altering excitability of the neurons and the strengths of their synaptic connections. In networks of identifiable neurons, these modulatory actions can be evaluated on a cell-by-cell and a synapse-by-synapse basis so that the modulatory actions can be understood within the context of the network. Investigations of neuromodulation in the lamprey spinal cord are hampered by the lack of uniquely identifiable neurons and the incomplete understanding of the locomotor network.

Various neuromodulators have been tested on fictive swimming in lamprey, and two will be considered here, serotonin and dopamine. These and other neuromodulators have been shown to produce alterations in the fictive swimming pattern such as changes in the cycle period, the amplitude of ventral root bursts, and the phase lag between bursts in different segments. The behavioral relevance of such changes in the swim pattern is not known, but may be associated with swimming under different conditions such as swimming upstream versus downstream, or are perhaps related to different behavioral contexts such as swimming in search of prey or on a spawning run. Until it is known under what conditions the neuromodulators are released endogenously, the behavioral meaning of neuromodulation in lamprey will not be understood.

\subsection{Serotonin (5-hydroxytryptamine)}

Nerve cells with serotonin (5-HT)-like immunoreactivity or 5-HT histofluorescence are located ventral to the central canal in the lamprey spinal cord (Ochi and Hosoya, 1974, Ochi et al., 1979, Harris-Warrick et al., 
1985, Van Dongen et al., 1985a). The processes of these cells form a dense plexus near the ventromedial surface and have also been traced into other regions of the spinal cord (Harris-Warrick et al., 1985). In addition to the spinal 5-HT cells, there are also 5-HT cells in the dorsal and ventral roots which send processes into the cord, and there are 5-HT neurons in the lamprey brainstem with descending projections to the spinal cord (Brodin et al., 1986). The ventromedial 5-HT plexus provides the densest region of 5-HT fibers in the cord by far. Motoneurons and interneurons have dendrites extending into this region, as shown by intracellular injections of Lucifer Yellow combined with 5-HT immunoreactivity (Van Dongen et al., 1985b). The varicosities of 5-HT fibers contain both large dense-core vesicles and smaller agranular vesicles, but do not exhibit synaptic specializations (Christenson et al., 1990).

The first report of the neuromodulatory action of 5-HT on fictive swimming in the lamprey came from HarrisWarrick and Cohen (1985). In a spinal cord/notochord preparation in which fictive swimming was induced by dglutamate, addition of 5-HT to the bath produced a concentration-dependent decrease in the fictive swim rate along with an increase in the intensity of the ventral root bursts and an increase in the phase lag between segments. The threshold concentration of 5-HT was in the range of 1-10 nM. Similar effects were induced by application of a 5-HT reuptake blocker, citalopram, indicating that endogenously released 5-HT acts on the locomotor network in a manner similar to exogenously applied 5-HT (Christenson et al., 1989). In freely swimming lamprey, injection of the animal with the 5-HT reuptake blocker clomipramine and the 5-HT precursor 5-hydroxy-I-tryptophan also produced a slowing of the swim rate (Kemnitz et al., 1995).

At the cellular level, it was first reported that 5-HT decreases the late afterspike hyperpolarization (late AHP) in motoneurons and lateral interneurons (Van Dongen et al., 1986). In a subsequent study, this effect was confirmed and also shown for CC interneurons and giant interneurons, but the late AHPs of dorsal cells and edge cells were not affected by 5-HT (Wallén et al., 1989). The late AHP in lamprey neurons results from a calciumdependent potassium current that is sensitive to apamin (Meer and Buchanan, 1992, Hill et al., 1992). The actions of 5-HT on fictive swimming and upon the late AHP appear to be due to receptors with some similarity to mammalian 5- $\mathrm{HT}_{1 \mathrm{~A}}$ receptors (Wikström et al., 1995). 5- $\mathrm{HT}$ does not affect the calcium plateau produced by tetraethylammonium in motoneurons, suggesting that 5-HT does not reduce the late AHP by reducing calcium entry. In addition to its effect on the late AHP, it was shown that 5-HT slightly hyperpolarizes most cells and reduces the chemical component of EPSPs from reticulospinal Müller cells to spinal neurons (including identified reticulospinal Müller cells and identified classes of spinal neurons) by a presynaptic mechanism (Buchanan and Grillner, 1991). A presynaptic action was supported by an electron microscopic study of Müller axons (Shupliakov et al., 1995). The EPSPs from dorsal cells to giant interneurons are also reduced by 5-HT and this effect may be mediated by a presynaptic reduction of calcium currents in the dorsal cells (el Manira et al., 1997).

The reduction of the late AHP of spinal neurons by 5-HT has been proposed to be the mechanism of action for the slowing of the fictive swimming rhythm by prolonging the burst duration of the CC interneurons. If the late AHP is reduced, the summation of the late AHP will not be able to terminate the train of action potentials in the CC interneurons (Grillner et al., 1988, Matsushima and Grillner, 1992, Schotland and Grillner, 1993, el Manira et al., 1994). One problem with this hypothesis is that 5-HT reduces the late AHP of both lateral interneurons and CC interneurons (Wallén et al., 1989). As shown in computer simulations, these cell classes have opposite effects on network cycle period: an increased excitatory level of lateral interneurons speeds the network, while an increased excitatory level of CC interneurons slows the network (Buchanan, 1992). Thus, a decreased late AHP in lateral interneurons will tend to speed the network while a decreased late AHP in CC interneurons will slow the network, and 5-HT acts on both cell types. A second problem with the hypothesis is that at normal swim speeds of 1-3 swim cycles per s (fictive and free swimming rate of 200-300 mm /chthyomyzon unicuspis), most spinal neurons fire only about 1 spike per cycle, and so burst termination by summation of the late AHPs in a train of spikes seems unlikely to be a significant mechanism in controlling cycle duration (Buchanan and Cohen, 
1982, Buchanan and Kasicki, 1995). Application of apamin, a selective blocker of the late AHP, has relatively little effect on cycle period during normal swim rates (Meer and Buchanan, 1992, el Manira et al., 1994), although it can reduce slower rates of fictive swimming (el Manira et al., 1994). Clearly, we need to know more about the actions of 5-HT on the various cell types and synapses in the lamprey spinal cord to fully understand its network actions. Of particular interest is the observation that 5-HT can induce slow periodic barrages of IPSPs in motoneurons in the quiescent cord (Harris-Warrick and Cohen, 1985). The identity of the inhibitory interneurons responsible for these IPSPs is not known. If these cells have access to the locomotor network, they could be regulating the overall burst rate of swimming.

\subsection{Dopamine}

Dopamine-like immunoreactivity and catecholamine histofluorescence are present in neurons and processes within the lamprey spinal cord. Dopaminergic neurons are found just below the central canal, each with a process extending to the central canal (Ochi et al., 1979, McPherson and Kemnitz, 1994; Pierre et al., 1997). In addition, there are more ventrally-located neurons that show both dopamine and 5-HT immunoreactivity suggesting co-localization in some neurons (Schotland et al., 1995). Application of dopamine to the spinal cord/notochord preparation during fictive swimming alters the swim rate. The first report found that dopamine (5-100 $\mu \mathrm{M}$ ) initially speeded the swim rate before disrupting the bursting (Harris-Warrick and Cohen, 1985). More recently, it was found that low concentrations of dopamine $(0.1-1 \mu \mathrm{M})$ speeded fictive swimming while higher concentrations (10 $\mu \mathrm{M}-1 \mathrm{mM})$ slowed the swim rate, while the highest concentrations $(100 \mu \mathrm{M}-1 \mathrm{mM})$ tended to disrupt the swim rhythm (McPherson and Kemnitz, 1994) (Fig. 8A). Using only a high concentration $(50 \mu \mathrm{M})$, a third study has confirmed the slowing effect (Schotland et al., 1995). The speeding of fictive swimming, but not the slowing, can also be elicited with apomorphine, a $D_{1} / D_{2}$ agonist, while selective $D_{2}$ antagonists can block the speeding produced by dopamine. However, neither $D_{1}$ nor $D_{2}$ antagonists can block the slowing of swimming produced by higher dopamine concentrations. These results suggest that the speeding is a selective action at $D_{2}$ receptors and that the slowing is a non-selective action at sites other than dopamine receptors (Kemnitz, 1994, Kemnitz et al., 1994). The speeding of fictive swimming by dopamine has been corroborated by injections of apomorphine into intact lampreys, which produced an increased frequency of body waves during free swimming behavior (Kemnitz et al., 1995).

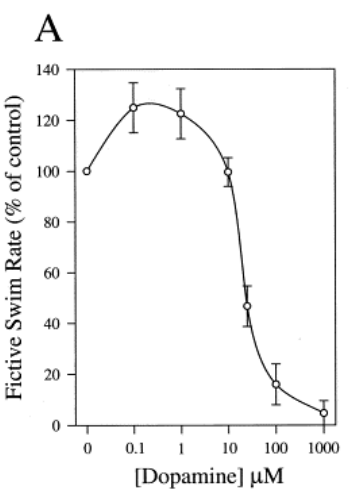

\section{B}
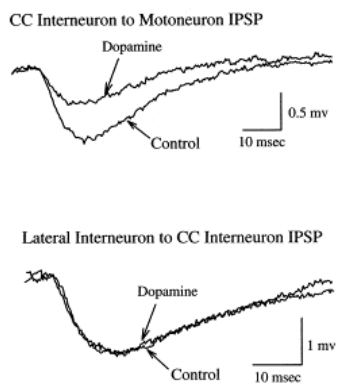

Fig. 8. Dopamine modulation of fictive swim rate and inhibitory synaptic potentials. (A) The rate of fictive swimming is increased by low concentrations of dopamine and decreased by higher concentrations. The speeding appears to be due to selective activation of $D_{2}$ dopamine receptors while the slowing is not blocked by a variety of dopamine antagonists and therefore may not be a selective dopamine action. (B) Dopamine reduces IPSPs in the lamprey spinal cord and appears to be selective for presynaptic cell type. As shown here, dopamine reduced the output IPSPs of CC interneurons but not those of lateral interneurons (a modified from McPherson and Kemnitz 1994; B modified from Kemnitz 1994). 
In an attempt to understand how dopamine is affecting the swim network, Kemnitz examined the cellular and synaptic actions of dopamine on identified cell classes in the lamprey spinal cord (Kemnitz, 1994, Kemnitz et al., 1994, Kemnitz, 1997). Synaptic potentials between identified pairs of cell classes appear to be selectively affected by dopamine. The output IPSPs produced by CC interneurons were reduced by dopamine but the output IPSPs of lateral interneurons were not (Fig. 8B). In general, EPSPs were not affected by dopamine, including those from giant interneurons, excitatory CC interneurons, and reticulospinal neurons. Dopamine also reduced the late AHP in some types of spinal neuron classes but not others. Dopamine consistently reduced the late AHPs in motoneurons, edge cells, dorsal cells, and giant interneurons while showing no effect on the late AHPs of lateral interneurons and CC interneurons (Fig. 9A). Dopamine was also shown to shift the spike frequency versus current (F-I) curve in the affected cells, but not in those cells showing no late AHP reduction (Fig. 9B). Thus, cells thought to be primarily responsible for the locomotor rhythm (lateral interneurons and CC interneurons) showed no reduction of their late AHPs, nor any shift in their F-I curves. The reduction of the late AHP appears to be due to a reduction in calcium influx, because dopamine reduced calcium action potentials and calcium plateaus in cells which also showed a reduction of the late AHP. Dopamine had little or no consistent effect on the resting membrane potential, the input resistance, the spike threshold current, or spike amplitude and duration in any of the identified cell classes (Kemnitz, 1994, Kemnitz et al., 1994, Kemnitz, 1997). The reduction of the late AHP and the reduction of calcium plateaus have also been reported in a study using unidentified spinal neurons (Schotland et al., 1995). This latter study also revealed that the reduction of the late AHP results from selective $D_{2}$ receptor activation.

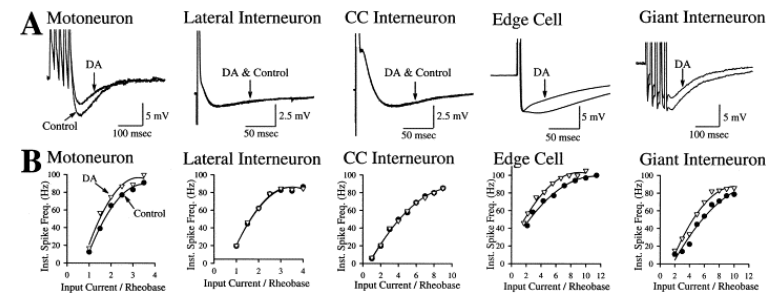

Fig. 9. Selective action of dopamine (DA) on the late afterspike hyperpolarization (late AHP) and firing frequencies in different classes of spinal neurons. (A) The late AHPs before and after application of dopamine. The late AHPs of lateral interneurons and CC interneurons were not affected by dopamine; the late AHPs of the other cell types were reduced by dopamine. For the motoneuron and giant interneuron, trains of spikes were used to summate the late AHPs to make them more apparent. (B) For a different set of representative neurons, the instantaneous spike frequency versus the current injection normalized to rheobase is plotted before (filled circles) and after dopamine application (open triangles). Again, lateral interneurons and CC interneurons were not affected by dopamine, but the other cell types exhibited an upward shift of the plots indicating that for a given level of current injection, the cells fired at a higher frequency (modified from Kemnitz 1994).

Based on the lack of effect of dopamine on the late AHPs of lateral interneurons and CC interneurons, the two cell types proposed to play important roles in rhythmogenesis, the speeding effect of dopamine may therefore occur mainly by its action of weakening the output synapses of inhibitory CC interneurons (Kemnitz, 1994, Kemnitz, 1997). In computer simulations, selective weakening of the output IPSPs of CC interneurons results in a speeding of the proposed locomotor network (Buchanan, 1992, Kemnitz, 1994). If dopamine also reduced the output IPSPs of lateral interneurons, then dopamine's effects would be more difficult to predict since weakening of the output IPSPs of lateral interneurons would slow the network.

\subsection{Neuromodulation summary}

Dopamine and 5-HT each have a number of actions in the lamprey spinal cord that are to some extent opposite in character. At the level of swimming of the intact lamprey and at the level of fictive swimming in the isolated spinal cord, the two neuromodulators have opposite effects on the rate of swimming activity: dopamine (at low 
concentrations) speeds swimming and 5-HT slows swimming. At the cellular level, both modulators reduce the late AHP in motoneurons and giant interneurons, but otherwise their target cells are different: dopamine affects edge cells and dorsal cells but not CC interneurons and lateral interneurons, 5 -HT affects CC interneurons and lateral interneurons but not edge cells and dorsal cells. At the synaptic level, dopamine acts mainly to reduce IPSPs, while 5-HT acts mainly to reduce EPSPs. In sum, these two neuromodulatory systems appear to have different behavioral consequences as well as different cellular and synaptic targets and mechanisms of action. Clearly, however, the story is somewhat more complex since there are some cell types in which both neuromodulators reduce the late AHP (motoneurons and giant interneurons), and there is immunohistological evidence that the two substances can be co-localized to the same neurons in the ventral spinal cord (Schotland et al., 1995).

In addition to 5-HT and dopamine, work has also been done on other neuromodulators present in the lamprey spinal cord such as GABA (Matsushima et al., 1993, Tegnér et al., 1993), neurotensin (Barthe and Grillner, 1995), glutamate metabotropic receptors (Krieger et al., 1994), and substance P (Parker and Grillner, 1996, Parker and Grillner, 1998). Neuromodulators are of interest not only from the viewpoint of understanding how neuronal networks are modified to produce adaptive behavior but also from the viewpoint of testing our understanding of how the network actually functions. As yet, no completely satisfying picture has emerged of how a particular neuromodulator exerts its actions in the lamprey. Again, this is due in large part to the lack of uniquely identifiable nerve cells in the spinal cord and the somewhat coarse divisions of spinal neurons into various classes. Subtle differences in effects of neuromodulators are often lost as it is usually assumed that the actions of a neuromodulator will be the same for all neuronal types in the spinal cord.

\section{Regeneration in the lamprey nervous system}

In lower vertebrates, the spinal cord shows some ability to recover from transection by growing axons across the lesion (Windle, 1956, Clemente, 1964). In lamprey, studies have demonstrated that functional recovery of motor and sensory behavior can occur some weeks after spinal transection (Rovainen, 1976, Selzer, 1978). In addition, it has been shown that several weeks after spinal transection, fictive swimming in the isolated spinal cord can show phase coupling across the lesion site (Cohen et al., 1988) and that the brainstem can initiate fictive swimming in the spinal cord caudal to the lesion (McClellan, 1990). This capacity for functional recovery in the lamprey and the identifiability of reticulospinal cells and spinal neuron classes have led to a number of studies examining regeneration in the lamprey spinal cord using these identifiable cells. The use of identifiable cells of lamprey have permitted an assessment of morphological changes of known cells after axotomy and regeneration and an assessment of the specificity of synaptic regeneration.

\subsection{Axon regeneration}

After determining the characteristic positions of the axons of each of the Müller and Mauthner cells in the spinal cord (Rovainen, 1967a) (Fig. 1), Rovainen used this information to follow the regeneration of these axons after complete spinal transections in larval sea lamprey (Rovainen, 1976). Rostral to the transection, the axons of the Müller and Mauthner cells were in their normal positions and thus could be easily identified. By using light microscopic serial tracing of the identified axons into and past the scar of the transection, it was possible to determine the extent and course of the axonal regeneration. Many of the identified axons grew into and through the scar but some turned away from the scar and regenerated in the opposite direction of their normal projection. Axons which grew through the scar were often found in abnormal positions within the cord and often split into multiple branches. Other studies, using intracellular dye injections into Müller and Mauthner cells, confirmed that Müller and Mauthner cells regenerate across complete spinal transections, but usually no attempt was made in these subsequent studies to identify the cells with regard to unique individuals (Borgens et al., 1981, Wood and Cohen, 1981). 
Selzer and his colleagues extended Rovainen's observations in a series of histological, physiological, and behavioral studies of regeneration using identified reticulospinal neurons and spinal neuron classes. They made use of the easy accessibility of the dorsal cells to characterize the morphological and electrophysiological changes that occur in these cells over long periods after axotomy (Yin et al., 1981). This study included morphological measurements on $\mathbf{3 3 0 0}$ dorsal cells and intracellular electrophysiological measurements on 800 dorsal cells. They found that about 3 weeks after axotomy, dorsal cells exhibited a decrease in basophilia, an increase in nucleus eccentricity, and an increase in the ratio of nucleus size to soma size. Lagging about one to two weeks behind these morphological changes were changes in the electrical properties of the cells. The axotomized dorsal cells exhibited an increase in input resistance, a less negative resting potential, an increase in spike threshold, a spike broadening, and an increase in axonal conduction velocity. This type of analysis was later extended to giant interneurons and lateral interneurons (Yin et al., 1987).

Yin and Selzer (1983) then examined the regeneration of Müller and Mauthner cells and classes of spinal neurons using intracellular injections of horseradish peroxidase (HRP) to reveal cell morphology. They identified the Mauthner axon by its position in the cord and the $I_{2}$ axon by its position and its bursting response to spinal cord stimulation (Section 3), and they found that these axons generally regenerated only a few millimeters past a spinal cord lesion. They also injected spinal neurons with HRP including dorsal cells, giant interneurons, lateral interneurons, edge cells, and CC interneurons. These studies demonstrated that all of these classes of cells exhibited the ability to regenerate across a lesion. Thus, axonal regeneration appears to be a general feature of lamprey spinal neurons. Giant interneuron axons grew in the correct direction even if they began regenerating in the wrong direction, and the lesion itself did not determine the direction of growth because double lesions, one rostral and one caudal to the giant interneurons, did not misdirect their regenerating axons toward the correct contralateral and rostral direction (Yin et al., 1984).

More recently, Selzer and colleagues have used identified reticulospinal cells to examine the contributions of cytoskeletal elements to regeneration. When Müller cells are axotomized close to the cell body, they tend to regenerate axons from ectopic dendritic sites and this phenomenon is associated with changes in immunostaining of dendrites for cytoskeletal proteins showing that they lose their dendritic character and become more axonal (Hall et al., 1997). In another study by this group exploiting the identifiability of reticulospinal cells (Jacobs et al., 1997), it was found that different Müller cells have different intrinsic abilities to regenerate and this ability is well-correlated to the upregulation of a particular neurofilament subunit mRNA.

\subsection{Specificity of synaptic regeneration}

Mackler and Selzer (1987) used the known monosynaptic dual electrical/chemical excitatory synapses from giant interneurons to more rostral giant interneurons (Fig. 3B) to test whether functional synaptic connections could be re-established by regenerated giant interneuron axons (Fig. 10). They found that $17 \%$ (8 of 47 ) of giant interneuron-giant interneuron pairs separated by a transection scar demonstrated monosynaptic composite EPSPs, compared with about $50 \%$ of pairs in normal animals. They also examined inputs to lateral interneurons from identified Müller cells $\left(B_{2-4}\right)$ and found that these connections had also recovered in some animals and that Müller cells which normally do not connect to lateral interneurons also did not do so in regenerated animals. This argument for specificity in the regeneration of synaptic connections was supported by other specific pairs of cells. In addition to Selzer's studies, Currie and Ayers (1987) demonstrated functional regeneration of the identified Müller cell, $I_{1}$. When stimulated, this Müller cell causes flexion of the contralateral dorsal fins. After spinal transection, this response was initially abolished and then recovered after 11 weeks. 


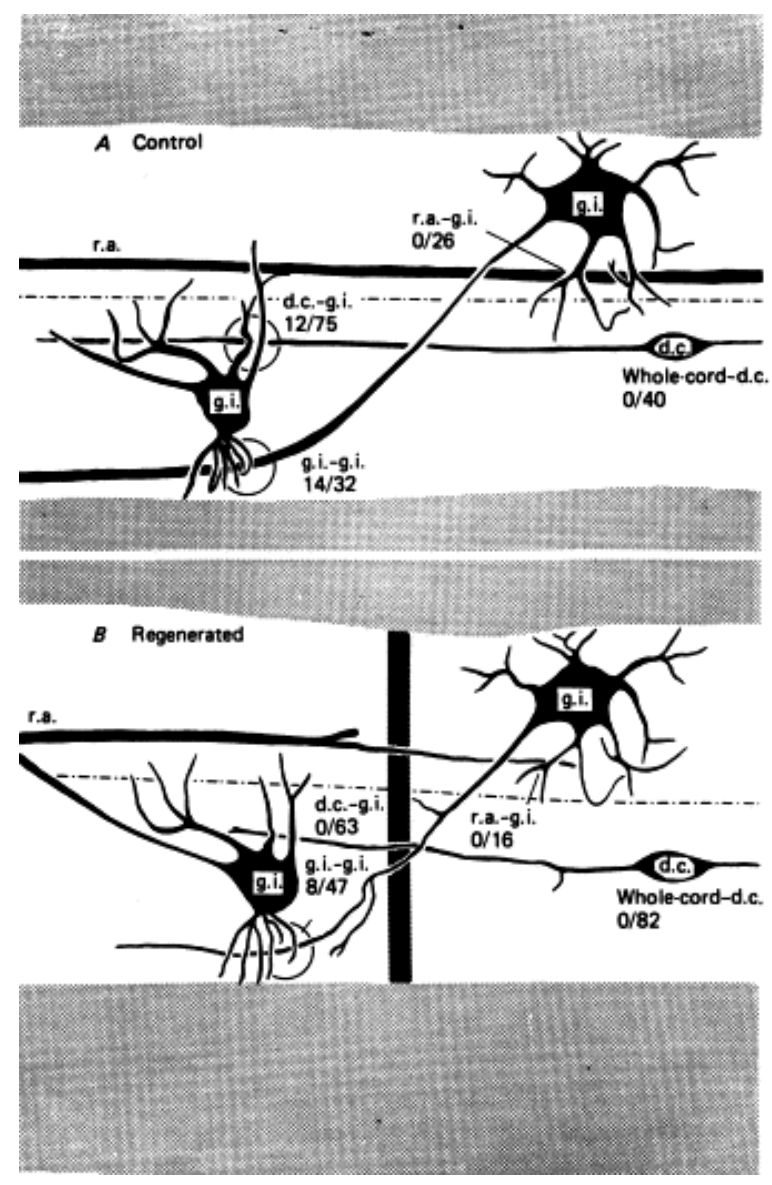

Fig. 10. Regeneration of synaptic interactions between neurons of identified neuron classes in the lamprey spinal cord. (A) In the normal spinal cord, giant interneurons (g.i.) project rostrally on the opposite side of the cord where they make excitatory synapses with about $50 \%$ of the giant interneurons. Dorsal cells (d.c.) make monosynaptic connections to about $15 \%$ of giant interneurons but never showed psps after whole cord stimulation. Giant interneurons never received input from medial reticulospinal axons (r.a.). Fractions represent the number of observed synaptic interactions of the total pairs tested. (B) Several weeks after a complete spinal transection (vertical bar), the axons of giant interneurons, dorsal cells, and reticulospinal cells regenerated across the transection. Regenerated giant interneuron axons made excitatory synaptic contacts with other giant interneurons, but dorsal cells did not make new synapses onto giant interneurons. Medial reticulospinal axons still did not make connections to giant interneurons, and whole cord stimulation still did not produce psps in dorsal cells (from Mackler and Selzer 1987; used with permission of publisher).

\subsection{Regeneration summary}

While it is not understood how functional recovery actually occurs in the lamprey, the use of identified cell classes has clearly established that descending reticulospinal cells and spinal neurons can regenerate across a spinal cord lesion for limited distances and make functional synapses. For both the reticulospinal cells and the giant interneurons, there is evidence for selective synapse formation with the correct target cells. Spinal cord regeneration is functional in that it can restore coupling of swim pattern generators across the lesion (Cohen et al., 1988). While we do not yet know which regenerated synapses are crucial for re-establishing phase coupling of fictive swimming across the lesion, this question could be addressed by determining the regeneration of synapses by the cell types that participate in locomotion such as the lateral interneurons and CC interneurons. 


\section{Conclusion}

The lamprey brainstem and spinal cord offer convenient preparations for investigating the structure and function of the vertebrate nervous system. While several uniquely identifiable nerve cells exist within the brainstem of the lamprey, the variability of cell positions in the spinal cord has thus far precluded the recognition of unique spinal neurons. However, classes of nerve cells can be readily defined and characterized within the lamprey spinal cord. The unique identifiability of the reticulospinal nerve cells of the brainstem has been exploited to some extent in investigations of the patterns of sensory input to these cells and the patterns of their outputs to spinal neurons, but no doubt these cells could be used much more effectively in exploring their roles in descending control of the spinal cord. While the ability to readily identify classes of spinal nerve cells has led to progress in understanding the cellular and synaptic mechanisms of locomotor activity in the spinal cord and in demonstrating the degree and specificity of regeneration within the lamprey, the lack of uniquely identifiable cells within the lamprey spinal cord has certainly hampered progress in these areas, especially in understanding of how neuromodulation of the locomotor network is accomplished.

\section{Acknowledgements}

I would like to thank Duane McPherson for reading the manuscript and providing helpful comments. The author's research is supported in part by NIH grants NS-35327 and NS-35725.

\section{References}

Alford et al., 1990. S. Alford, T.L. Williams, K.A. Sigvardt. Effects of bicuculline and strychnine on synaptic inputs to edge cells during fictive locomotion. Brain Res., 509 (1990), pp. 137-140

Alford et al., 1991. S. Alford, J. Christenson, S. Grillner. Presynaptic $G_{A B A_{A}}$ and $G_{A B A_{B}}$ receptor-mediated phasic modulation in axons of spinal motor interneurons. Eur. J. Neurosci., 3 (1991), pp. 107-117

Barthe and Grillner, 1995. J.Y. Barthe, S. Grillner. Neurotensin-induced modulation of spinal neurons and fictive locomotion in the lamprey. J. Neurophysiol., 73 (1995), pp. 1308-1312

Batueva et al., 1990. V. Batueva, E.I. Suderevskaya, N.P. Vesselkin, J. Pierre, J. Reperant. Localisation of GABAimmunopositive cells in the river lamprey spinal cord. J. Hirnfors., 31 (1990), pp. 739-745

Batueva et al., 1999.

I. Batueva, E. Tsvetkov, A. Sagatelyan, J.T. Buchanan, N. Vesselkin, V. Adanina, E. Suderevskaya, J.P. Rio, J . Reperant. Physiological and morphological correlates of presynaptic inhibition in primary afferents of the lamprey spinal cord. Neuroscience, 88 (1999), pp. 975-987

Borgens et al., 1981. R.B. Borgens, E. Roederer, M.J. Cohen. Enhanced spinal cord regeneration in lamprey by applied electric fields. Science, 213 (1981), pp. 611-617

Brodin et al., 1986. L. Brodin, J.T. Buchanan, T. Hökfelt, S. Grillner, A.A.J. Verhofstad. A spinal projection of 5hydroxytryptamine neurons in the lamprey brainstem; evidence from combined retrograde tracing and immunohistochemistry. Neurosci. Lett., 67 (1986), pp. 53-57

Brodin et al., 1987. L. Brodin, J. Christenson, S. Grillner. Single sensory neurons activate excitatory amino acid receptors in the lamprey spinal cord. Neurosci. Lett., 75 (1987), pp. 75-79

Brodin et al., 1990. L. Brodin, N. Dale, J. Christenson, J. Storm-Mathisen, T. Hökfelt, S. Grillner. Three types of GABA-immunoreactive cells in the lamprey spinal cord. Brain Res., 508 (1990), pp. 172-175

Brodin et al., 1991. L. Brodin, H.G.C. Tråvén, A. Lansner, P. Wallén, Ö. Ekeberg, S. Grillner. Computer simulations of $\mathbf{N}$-methyl-d-aspartate receptor-induced membrane properties in a neuron model. $J$. Neurophysiol., 66 (1991), pp. 473-484

Buchanan, 1982. J.T. Buchanan. Identification of interneurons with contralateral, caudal axons in the lamprey spinal cord: synaptic interactions and morphology. J. Neurophysiol., 47 (1982), pp. 961-975

Buchanan, 1986. J.T. Buchanan. Premotor interneurons in the lamprey spinal cord: morphology, synaptic interactions and activities during fictive swimming. 
S. Grillner, P.S.G. Stein, D.G. Stuart, H. Forssberg, R.M. Herman (Eds.), Neurobiology of Vertebrate

Locomotion, MacMillan, London (1986), pp. 321-333

Buchanan, 1992. J.T. Buchanan. Neural network simulations of coupled locomotor oscillators in the lamprey spinal cord. Biol. Cybern., 66 (1992), pp. 367-374

Buchanan, 1993. J.T. Buchanan. Electrophysiological properties of identified classes of lamprey spinal neurons. J. Neurophysiol., 70 (1993), pp. 2313-2325

Buchanan, 1999. J.T. Buchanan. Commissural interneurons in rhythm generation and intersegmental coupling in the lamprey spinal cord. J. Neurophysiol., 81 (1999), pp. 2037-2045

Buchanan and Cohen, 1982. J.T. Buchanan, A.H. Cohen. Activities of identified interneurons, motoneurons, and muscle fibers during fictive swimming in the lamprey and effects of reticulospinal and dorsal cell stimulation. J. Neurophysiol., 47 (1982), pp. 948-960

Buchanan and Grillner, 1987. J.T. Buchanan, S. Grillner. Newly identified 'glutamate interneurons' and their role in locomotion in the lamprey spinal cord. Science, 236 (1987), pp. 312-314

Buchanan and Grillner, 1988. J.T. Buchanan, S. Grillner. A new class of small inhibitory interneurones in the lamprey spinal cord. Brain Res., 438 (1988), pp. 404-407

Buchanan and Grillner, 1991. J.T. Buchanan, S. Grillner. 5-Hydroxytryptamine depresses reticulospinal excitatory postsynaptic potentials in motoneurons of the lamprey. Neurosci. Lett., 112 (1991), pp. 7174

Buchanan and Kasicki, 1995. J.T. Buchanan, S. Kasicki. Activities of spinal neurons during brain stem-dependent fictive swimming in lamprey. J. Neurophysiol., 73 (1995), pp. 80-87

Buchanan and McPherson, 1995. J.T. Buchanan, D.R. McPherson. The neuronal network for locomotion in the lamprey spinal cord: Evidence for the involvement of commissural interneurons. J. Physiol. (Paris), 89 (1995), pp. 221-233

Buchanan et al., 1987a. J.T. Buchanan, L. Brodin, N. Dale, S. Grillner. Reticulospinal neurones activate excitatory amino acid receptors. Brain Res., 408 (1987), pp. 321-325

Buchanan et al., 1987b. J.T. Buchanan, L. Brodin, T. Hökfelt, P.A.M. Van Dongen, S. Grillner. Survey of neuropeptide-like immunoreactivity in the lamprey spinal cord. Brain Res., 408 (1987), pp. 299-302

Buchanan et al., 1989. J.T. Buchanan, S. Grillner, S. Cullheim, M. Risling. Identification of excitatory interneurons contributing to generation of locomotion in lamprey: structure, pharmacology, and function. J. Neurophysiol., 62 (1989), pp. 59-69

Buchanan et al., 1998. J.T. Buchanan, S. Kasicki, K.A. Quinlan. Effects of motoneuron stimulation in the lamprey spinal cord. Soc. Neurosci., 24 (1998), p. 1666

Christensen, 1983. B.N. Christensen. Distribution of electrotonic synapses on identified lamprey neurons: a comparison of a model prediction with an electron microscopic analysis. J. Neurophysiol., 49 (1983), pp. 705-716

Christensen and Teubl, 1979a. B.N. Christensen, W.P. Teubl. Estimates of cable parameters in lamprey spinal cord neurons. J. Physiol. (London), 297 (1979), pp. 299-318

Christensen and Teubl, 1979b. B.N. Christensen, W.P. Teubl. Localization of synaptic input on dendrites of a lamprey spinal cord neurone from physiological measurements of membrane properties. J. Physiol. (London), 297 (1979), pp. 319-333

Christenson and Grillner, 1991. J. Christenson, S. Grillner. Primary afferents evoke excitatory amino acid receptor-mediated EPSPs that are modulated by presynaptic $\mathrm{GABA}_{B}$ receptors in lamprey. $J$. Neurophysiol., 66 (1991), pp. 2141-2149

Christenson et al., 1988a. J. Christenson, A. Boman, P.-Å. Lagerbäck, S. Grillner. The dorsal cell, one class of primary sensory neuron in the lamprey spinal cord. I. Touch, pressure but no nociception - a physiological study. Brain Res., 440 (1988), pp. 1-8

Christenson et al., 1988b. J. Christenson, P.Å. Lagerbäck, S. Grillner. The dorsal cell, one class of primary sensory neuron in the lamprey spinal cord. II. A light- and electron microscopical study. Brain Res., 440 (1988), pp. 9-17 
Christenson et al., 1989. J. Christenson, J. Franck, S. Grillner. Increase in endogenous 5-hydroxytryptamine levels modulates the central network underlying locomotion in the lamprey spinal cord. Neurosci. Lett., 100 (1989), pp. 188-192

Christenson et al., 1990. J. Christenson, S. Cullheim, S. Grillner, T. Hökfelt. 5-Hydroxytryptamine immunoreactive varicosities in the lamprey spinal cord have no synaptic specializations - an ultrastructural study. Brain Res., 512 (1990), pp. 201-209

Christenson et al., 1991. J. Christenson, S. Alford, S. Grillner, T. Hökfelt. Co-localized GABA and somatostatin use different ionic mechanisms to hyperpolarize target neurons in the lamprey spinal cord. Neurosci. Lett., 134 (1991), pp. 93-97

Christenson et al., 1993. J. Christenson, R.H. Hill, F. Bongianni, S. Grillner. Presence of low voltage activated calcium channels distinguishes touch from pressure sensory neurons in the lamprey spinal cord. Brain Res., 608 (1993), pp. 58-66

Clarke et al., 1984. J.D.W. Clarke, B.P. Hayes, S.P. Hunt, A. Roberts. Sensory physiology, anatomy and immunohistochemistry of Rohon-Beard neurones in embryos of Xenopus laevis. J. Physiol. (London), 348 (1984), pp. 511-525

Clemente, 1964. C.D. Clemente. Regeneration in the vertebrate central nervous system. Int. Rev. Neurobiol., 6 (1964), pp. 257-301

Cochilla and Alford, 1997. A.J. Cochilla, S. Alford. Glutamate receptor-mediated synaptic excitation in axons of the lamprey. J. Physiol. (London), 499 (1997), pp. 443-457

Cohen and Wallén, 1980. A.H. Cohen, P. Wallén. The neuronal correlate of locomotion in fish. 'Fictive swimming' induced in an in vitro preparation of the lamprey spinal cord. Exp. Brain Res., 41 (1980), pp. 11-18

Cohen and Harris-Warrick, 1984. A.H. Cohen, R.M. Harris-Warrick. Strychnine eliminates alternating motor output during fictive locomotion in the lamprey. Brain Res., 293 (1984), pp. 164-167

Cohen et al., 1988. A.H. Cohen, S.A. Mackler, M.E. Selzer. Behavioral recovery following spinal transection: functional regeneration in the lamprey CNS. Trends Neurosci., 11 (1988), pp. 227-231

Cohen et al., 1992. A.H. Cohen, G.B. Ermentrout, T. Kiemel, N. Kopell, S.A. Sigvardt, T.L. Williams. Modelling of intersegmental coordination in the lamprey central pattern generator for locomotion. Trends in Neurosci., 15 (1992), pp. 434-438

Currie and Ayers, 1987. S.N. Currie, J. Ayers. Plasticity of fin command system function following spinal transection in larval sea lamprey. Brain Res., 415 (1987), pp. 337-341

Currie and Carlsen, 1987a. S.N. Currie, R.C. Carlsen. Modulated vibration-sensitivity of lamprey Mauthner neurons. J. Exp. Biol., 129 (1987), pp. 41-51

Currie and Carlsen, 1987b. S.N. Currie, R.C. Carlsen. Functional significance and neural basis of larval lamprey startle behaviour. J. Exp. Biol., 133 (1987), pp. 121-135

Dale, 1986. N. Dale. Excitatory synaptic drive for swimming mediated by amino acid receptors in the lamprey. J. Neurosci., 6 (1986), pp. 2662-2675

Ekeberg et al., 1991. Ö. Ekeberg, P. Wallén, A. Lansner, H. Tråvén, L. Brodin, S. Grillner. A computer based model for realistic simulations of neural networks. I. The single neuron and synaptic interaction. Biol. Cybern., 65 (1991), pp. 81-90

el Manira and Bussières, 1997. A. el Manira, N. Bussières. Calcium channel subtypes in lamprey sensory and motor neurons. J. Neurophysiol, 78 (1997), pp. 1340-1344

el Manira et al., 1994. A. el Manira, J. Tegnér, S. Grillner. Calcium-dependent postassium channels play a critical role for burst termination in the locomotor network in lamprey. J. Neurophysiol., 72 (1994), pp. 18521861

el Manira et al., 1996. A. el Manira, J. Tegnér, S. Grillner. Locomotor-related presynaptic modulation of primary afferents in the lamprey. Euro. J. Neurosci., 9 (1996), pp. 696-705

el Manira et al., 1997. A. el Manira, W. Zhang, E. Svensson, N. Bussières. 5-HT inhibits calcium current and synaptic transmission from sensory neurons in lamprey. J. Neurosci., 17 (1997), pp. 1786-1794 
Fetcho, 1990. J.R. Fetcho. Morphological variability, segmental relationships, and functional role of a class of commissural interneurons in the spinal cord of goldfish. J. Comp. Neurol., 299 (1990), pp. 283-298

Gad et al., 1998. H. Gad, P. Low, E. Zotava, L. Brodin, O. Shupliakov. Dissociation between Ca ${ }^{2+}$-triggered synaptic vesicle exocytosis and clathrin-mediated endocytosis at a central synapse. Neuron, 21 (1998), pp. 607-617

Grillner and Wallén, 1980. S. Grillner, P. Wallén. Does the central pattern generation for locomotion in lamprey depend on glycine inhibition? Acta Physiol. Scand., 110 (1980), pp. 103-105

Grillner and Wallén, 1985. S. Grillner, P. Wallén. The ionic mechanisms underlying $\mathbf{N}$-methyl-d-aspartate receptor-induced, tetrodotoxin-resistant membrane potential oscillations in lamprey neurons active during locomotion. Neurosci. Lett., 60 (1985), pp. 289-294

Grillner et al., 1982. S. Grillner, A. McClellan, K. Sigvardt. Mechanosensitive neurons in the spinal cord of the lamprey. Brain Res., 235 (1982), pp. 169-173

Grillner et al., 1984. S. Grillner, T. Williams, P.Å. Lagerbäck. The edge cell, a possible intraspinal mechanoreceptor. Science, 223 (1984), pp. 500-503

Grillner et al., 1988. S. Grillner, J.T. Buchanan, A. Lansner. Simulation of the segmental burst generating network for locomotion in lamprey. Neurosci. Lett., 89 (1988), pp. 31-35

Hall et al., 1997. G.F. Hall, J. Yao, M.E. Selzer, K.S. Kosik. Cytoskeletal changes correlated with the loss of neuronal polarity in axotomized lamprey central neurons. J. Neurocytol., 26 (1997), pp. 733-753

Harris-Warrick and Cohen, 1985. R.M. Harris-Warrick, A.H. Cohen. Serotonin modulates the central pattern generator for locomotion in the isolated lamprey spinal cord. J. Exp. Biol., 116 (1985), pp. 27-46

Harris-Warrick and Marder, 1991. R.M. Harris-Warrick, E. Marder. Modulation of neural networks for behavior. Annu. Rev. Neurosci., 14 (1991), pp. 39-58

Harris-Warrick et al., 1985. R.M. Harris-Warrick, J.C. McPhee, J.A. Filler. Distribution of serotonergic neurons and processes in the lamprey spinal cord. Neurosci., 14 (1985), pp. 1127-1140

Hill et al., 1985. R.H. Hill, P. Århem, S. Grillner. Ionic mechanisms of 3 types of functionally different neurons in the lamprey spinal cord. Brain Res., 358 (1985), pp. 40-52

Hill et al., 1992. R. Hill, T. Matsushima, J. Schotland, S. Grillner. Apamin blocks the slow AHP in lamprey and delays termination of locomotor bursts. Neuroreport, 3 (1992), pp. 943-945

Homma, 1979. S. Homma. Conductance changes during bath application of $\beta$-alanine and taurine in giant interneurons of the isolated lamprey spinal cord. Brain Res., 173 (1979), pp. 287-293

Homma, 1985. S. Homma. Effects of bath-applied excitatory amino acids and their analogs on spinal interneurons of the lamprey. Brain Res., 344 (1985), pp. 96-102

Homma and Rovainen, 1978. S. Homma, C.M. Rovainen. Conductance increases produced by glycine and $\boldsymbol{\nu -}$ aminobutyric acid in lamprey interneurons. J. Physiol. (London), 279 (1978), pp. 231-252

Jacobs et al., 1997. A.J. Jacobs, G.P. Swain, J.A. Snedeker, D.S. Pijak, L.J. Gladstone, M.E. Selzer. Recovery of neurofilament expression selectively in regenerating reticulospinal neurons. J. Neurosci., 17 (1997), pp. 5206-5220

Kahn, 1982. J.A. Kahn. Patterns of synaptic inhibition in motoneurons and interneurons during fictive swimming in the lamprey, as revealed by $\mathrm{Cl}^{-}$injections. J. Comp. Physiol., A147 (1982), pp. 189-194

Kasicki and Grillner, 1986. S. Kasicki, S. Grillner. Müller cells and other reticulospinal neurones are phasically active during fictive locomotion in the isolated nervous system of the lamprey. Neurosci. Lett., 69 (1986), pp. 239-243

Kasicki et al., 1989. S. Kasicki, S. Grillner, Y. Ohta, R. Dubuc, L. Brodin. Phasic modulation of reticulospinal neurones during fictive locomotion and other types of spinal motor activity in lamprey. Brain Res., 484 (1989), pp. 203-216

Kemnitz, 1994. Kemnitz, C.P., 1994. Dopaminergic modulation of spinal neurons in the lamprey: network, cellular, and synaptic effects. Ph.D. Thesis, Marquette University.

Kemnitz, 1997. C.P. Kemnitz. Dopaminergic modulation of spinal neurons and synaptic potentials in the lamprey spinal cord. J. Neurophysiol., 77 (1997), pp. 289-298 
Kemnitz et al., 1994. C.P. Kemnitz, J.T. Buchanan, W. Merlau, I.V. Batueva. Dopaminergic modulation of the swim network and spinal neurons in lamprey. Soc. Neurosci., 20 (1994), p. 1591

Kemnitz et al., 1995. C.P. Kemnitz, T.R. Strauss, D.M. Hosford, J.T. Buchanan. Modulation of swimming in the lamprey, Petromyzon marinus, by serotonergic and dopaminergic drugs. Neurosci. Lett., 201 (1995), pp. $115-118$

Kimmel et al., 1982. C.B. Kimmel, S.L. Powell, W.K. Metcalfe. Brain neurons which project to the spinal cord in young larvae of the zebrafish. J. Comp. Neurol., 205 (1982), pp. 112-127

Krieger et al., 1994. P. Krieger, J. Tegnér, A. el Manira, S. Grillner. Effects of metabotropic glutamate receptor activation on the cellular and network level in the lamprey spinal cord. Neuroreport, 5 (1994), pp. $1760-1762$

Lee and Eaton, 1991. R.K.K. Lee, R.C. Eaton. Identifiable reticulospinal neurons of the adult zebrafish, Brachydanio rerio. J. Comp. Neurol., 304 (1991), pp. 34-52

Lee et al., 1993. R.K.K. Lee, R.C. Eaton, S.J. Zottoli. Segmental arrangement of reticulospinal neurons in the goldfish hindbrain. J. Comp. Neurol., 329 (1993), pp. 539-556

Leonard and Wickelgren, 1986. J.P. Leonard, W.O. Wickelgren. Prolongation of calcium action potentials by $\mathbf{Y}^{-}$ aminobutyric acid in primary sensory neurones of lamprey. J. Physiol. (London), 375 (1986), pp. 481497

Mackler and Selzer, 1987. S.A. Mackler, M.E. Selzer. Specificity of synaptic regeneration in the spinal cord of the larval sea lamprey. J. Physiol. (London), 388 (1987), pp. 183-198

Martin and Wickelgren, 1971. A.R. Martin, W.O. Wickelgren. Sensory cells in the spinal cord of the sea lamprey. J. Physiol. (London), 212 (1971), pp. 65-83

Martin and Ringham, 1975. A.R. Martin, G.L. Ringham. Synaptic transfer at a vertebrate central nervous system synapse. J. Physiol. (London), 251 (1975), pp. 409-426

Martin et al., 1970. A.R. Martin, W.O. Wickelgren, R. Berànek. Effects of iontophoretically applied drugs on spinal interneurones of the lamprey. J. Physiol. (London), 207 (1970), pp. 653-665

Matsushima and Grillner, 1992. T. Matsushima, S. Grillner. Local serotonergic modulation of calciumdependent potassium channels controls intersegmental coordination in the lamprey spinal cord. J. Neurophysiol., 67 (1992), pp. 1683-1690

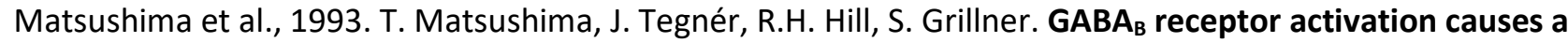
depression of low- and high-voltage-activated $\mathrm{Ca}^{2+}$ currents, postinhibitory rebound, and postspike afterhyperpolarization in lamprey neurons. J. Neurophysiol., 70 (1993), pp. 2606-2619

Matthews and Wickelgren, 1979. G. Matthews, W.O. Wickelgren. Glycine, GABA and synaptic inhibition of reticulospinal neurones of lamprey. J. Physiol. (London), 293 (1979), pp. 393-415

McClellan, 1988. A.D. McClellan. Brainstem command systems for locomotion in the lamprey: localization of descending pathways in the spinal cord. Brain Res., 457 (1988), pp. 338-349

McClellan, 1990. A.D. McClellan. Locomotor recovery in spinal-transected lamprey: role of functional regeneration of descending axons from brainstem locomotor command neurons. Neuroscience, 37 (1990), pp. 781-798

McClellan and Grillner, 1983. A.D. McClellan, S. Grillner. Initiation and sensory gating of 'fictive' swimming and withdrawal responses in an in vitro preparation of the lamprey spinal cord. Brain Res., 269 (1983), pp. $237-250$

McClellan and Grillner, 1984. A.D. McClellan, S. Grillner. Activation of 'fictive swimming' by electrical microstimulation of brainstem locomotor regions in an in vitro preparation of the lamprey central nervous system. Brain Res., 300 (1984), pp. 357-361

McClellan and Sigvardt, 1988. A.D. McClellan, K.A. Sigvardt. Features of entrainment of spinal pattern generators for locomotor activity in the lamprey spinal cord. J. Neurosci., 8 (1988), pp. 133-145

McPherson and Buchanan, 1995. D.R. McPherson, J.T. Buchanan. A low-power epi-fluorescence microscope for neurophysiologists. Soc. Neurosci., 21 (1995), p. 1077 
McPherson and Kemnitz, 1994. D.R. McPherson, C.P. Kemnitz. Modulation of lamprey fictive swimming and motoneuron physiology by dopamine, and its immunocytochemical localization in the spinal cord. Neurosci. Lett., 166 (1994), pp. 23-26

McPherson et al., 1994. D.R. McPherson, J.T. Buchanan, S. Kasicki. Effects of strychnine on fictive swimming in the lamprey: evidence for glycinergic inhibition, discrepancies with model predictions, and novel modulatory rhythms. J. Comp. Physiol., A175 (1994), pp. 311-321

Meer and Buchanan, 1992. D.P. Meer, J.T. Buchanan. Apamin reduces the late afterhyperpolarization of lamprey spinal neurons, with little effect on fictive swimming. Neurosci. Lett., 143 (1992), pp. 1-4

Metcalfe et al., 1986. W.K. Metcalfe, B. Mendelson, C.B. Kimmel. Segmental homologies among reticulospinal neurons in the hindbrain of the zebrafish larva. J. Comp. Neurol., 251 (1986), pp. 147-159

Miller and Selverston, 1979. J.P. Miller, A.I. Selverston. Rapid killing of single neurons by irradiation of intracellularly injected dye. Science, 206 (1979), pp. 702-704

Murphey et al., 1995. C.R. Murphey, L.E. Moore, J.T. Buchanan. Quantitative analysis of electrotonic structure and membrane properties of NMDA activated lamprey spinal neurons. Neural Comp., 7 (1995), pp. 486-506

Nakao and Ishizawa, 1987. T. Nakao, A. Ishizawa. Development of the spinal nerves in the lamprey: I. RohonBeard cells and interneurons. J. Comp. Neurol., 256 (1987), pp. 342-355

Ochi and Hosoya, 1974. J. Ochi, Y. Hosoya. Fluorescence microscopic differentiation of monoamines in the hypothalamus and spinal cord of the lamprey, using a new filter system. Histochemistry, 40 (1974), pp. 263-266

Ochi et al., 1979. J. Ochi, T. Yamamoto, Y. Hosoya. Comparative study of the monoamine neuron system in the spinal cord of the lamprey and hagfish. Arch. Histol. Jpn., 42 (1979), pp. 327-336

Ohta and Grillner, 1989. Y. Ohta, S. Grillner. Monosynaptic excitatory amino acid transmission from the posterior rhombencephalic reticular nucleus to spinal neurons involved in the control of locomotion in lamprey. J. Neurophysiol., 62 (1989), pp. 1079-1089

Ohta et al., 1991. Y. Ohta, R. Dubuc, S. Grillner. A new population of neurons with crossed axons in the lamprey spinal cord. Brain Res., 564 (1991), pp. 143-148

Parker and Grillner, 1996. D. Parker, S. Grillner. Tachykinin-mediated modulation of sensory neurons, interneurons, and synaptic transmission in the lamprey spinal cord. J. Neurophysiol., 76 (1996), pp. 4031-4039

Parker and Grillner, 1998. D. Parker, S. Grillner. Cellular and synaptic modulation underlying substance Pmediated plasticity of the lamprey locomotor network. J. Neurophysiol., 18 (1998), pp. 8095-8110

Parker et al., 1997. D. Parker, E. Svensson, S. Grillner. Substance P modulates sensory action potentials in the lamprey via a protein kinase C-mediated reduction of a 4-aminopyridine-sensitive potassium conductance. Euro. J. Neurosci., 9 (1997), pp. 2064-2076

Perrins and Roberts, 1995a. R. Perrins, A. Roberts. Cholinergic and electrical motoneuron-to-motoneuron synapses contribute to on-cycle excitation during swimming in Xenopus embryos. $J$. Neurophysiol., 73 (1995), pp. 1005-1012

Perrins and Roberts, 1995b. R. Perrins, A. Roberts. Cholinergic contribution to excitation in a spinal locomotor central pattern generator in Xenopus embryos. J. Neurophysiol., 73 (1995), pp. 1013-1019

Poon, 1980. M.L.T. Poon. Induction of swimming in lamprey by I-DOPA and amino acids. J. Comp. Physiol., A136 (1980), pp. 337-344

Ringham, 1975. G.L. Ringham. Localization and electrical characteristics of a giant synapse in the spinal cord of the lamprey. J. Physiol. (London), 251 (1975), pp. 395-407

Roberts, 1990. A. Roberts. How does a nervous system produce behaviour? A case study in neurobiology. Sci. Prog., 74 (1990), pp. 31-51

Rouse et al., 1998. D.T. Rouse, X. Quan, A.D. McClellan. Biophysical properties of descending brain neurons in larval lamprey. Brain Res., 779 (1998), pp. 301-308 
Rovainen, 1967a. C.M. Rovainen. Physiological and anatomical studies on large neurons of central nervous system of the sea lamprey (Petromyzon marinus). I. Müller and Mauthner cells. J.

Neurophysiol., 30 (1967), pp. 1000-1023

Rovainen, 1967b. C.M. Rovainen. Physiological and anatomical studies on large neurons of central nervous system of the sea lamprey (Petromyzon marinus). II. Dorsal cells and giant interneurons. J. Neurophysiol., 30 (1967), pp. 1024-1042

Rovainen, 1974a. C.M. Rovainen. Synaptic interactions of identified nerve cells in the spinal cord of the sea lamprey. J. Comp. Neurol., 154 (1974), pp. 189-206

Rovainen, 1974b. C.M. Rovainen. Synaptic interactions of reticulospinal neurons and nerve cells in the spinal cord of the sea lamprey. J. Comp. Neurol., 154 (1974), pp. 207-223

Rovainen, 1976. C.M. Rovainen. Regeneration of Müller and Mauthner axons after spinal transection in larval lampreys. J. Comp. Neurol., 168 (1976), pp. 545-554

Rovainen, 1978. C.M. Rovainen. Müller cells, 'Mauthner' cells, and other identified reticulospinal neurons in the lamprey. D.S. Faber, H. Korn (Eds.), Neurobiology of the Mauthner Cell, Raven Press, New York (1978), pp. 245-269

Rovainen, 1979a. C.M. Rovainen. Electrophysiology of vestibulospinal and vestibuloreticulospinal systems in lampreys. J. Neurophysiol., 42 (1979), pp. 745-766

Rovainen, 1979b. C.M. Rovainen. Neurobiology of lampreys. Physiol. Rev., 59 (1979), pp. 1007-1077

Rovainen, 1982. C.M. Rovainen. Neurophysiology. M.W. Hardisty, I.C. Potter (Eds.), The Biology of Lampreys, 4A, Academic Press, London (1982), pp. 1-136

Rovainen and Birnberger, 1971. C.M. Rovainen, K.L. Birnberger. Identification and properties of motoneurons to fin muscle of the sea lamprey. J. Neurophysiol., 34 (1971), pp. 974-982

Rovainen and Dill, 1984. C.M. Rovainen, D.A. Dill. Counts of axons in electron microscopic sections of ventral roots in lampreys. J. Comp. Neurol., 225 (1984), pp. 433-440

Rovainen et al., 1973. C.M. Rovainen, P.A. Johnson, E.A. Roach, J.A. Mankovsky. Projections of individual axons in lamprey spinal cord determined by tracings through serial sections. J. Comp. Neurol., 149 (1973), pp. 193-202

Russell and Wallén, 1983. D.F. Russell, P. Wallén. On the control of myotomal motoneurones during 'fictive swimming' in the lamprey spinal cord in vitro. Acta Physiol. Scand., 117 (1983), pp. 161-170

Schotland and Grillner, 1993. J.L. Schotland, S. Grillner. Effects of serotonin on fictive locomotion coordinated by a neural network deprived of NMDA receptor-mediated cellular properties. Exp. Brain Res., 93 (1993), pp. 391-398

Schotland et al., 1995. J. Schotland, O. Shupliakov, M. Wikström, L. Brodin, M. Srinivasan, Z.B. You, M. HerreraMarschitz, W. Zhang, T. Hökfelt, S. Grillner. Control of lamprey locomotor neurons by colocalized monoamine transmitters. Nature, 374 (1995), pp. 266-268

Selverston and Miller, 1982. A. Selverston, J.P. Miller. Application of a cell inactivation technique to the study of a small neural network. Trends Neurosci., 5 (1982), pp. 120-123

Selzer, 1978. M.E. Selzer. Mechanisms of functional recovery and regeneration after spinal cord transection in larval sea lamprey. J. Physiol. (London), 277 (1978), pp. 395-408

Selzer, 1979. M.E. Selzer. Variability in maps of identified neurons in the sea lamprey spinal cord examined by a wholemount technique. Brain Res., 163 (1979), pp. 181-193

Shupliakov et al., 1992. O. Shupliakov, P. Wallén, S. Grillner. Two types of motoneurons supplying dorsal fin muscles in lamprey and their activity during fictive locomotion. J. Comp. Neurol., 321 (1992), pp. 112123

Shupliakov et al., 1995. O. Shupliakov, V.A. Pieribone, H. Gad, L. Brodin. Synaptic vesicle depletion in reticulospinal axons is reduced by 5-hydroxytryptamine: direct evidence for presynaptic modulation of glutamatergic transmission. Eur. J. Neurosci., 7 (1995), pp. 1111-1116

Sigvardt et al., 1985. K.A. Sigvardt, S. Grillner, P. Wallén, P.A. Van Dongen. Activation of NMDA receptors elicits fictive locomotion and bistable membrane properties in the lamprey spinal cord. Brain Res., 336 (1985), pp. 390-395 
Spikes, 1991. J.D. Spikes. Applications of dye-sensitized photoreactions in neurobiology. Photochem. and Photobiol., 54 (1991), pp. 1079-1092

Tang and Selzer, 1979. D. Tang, M.E. Selzer. Projections of lamprey spinal neurons determined by the retrograde axonal transport of horseradish peroxidase. J. Comp. Neurol., 188 (1979), pp. 629-645

Tegnér et al., 1993. J. Tegnér, T. Matsushima, A. el Manira, S. Grillner. The spinal GABA system modulates burst frequency and intersegmental coordination in the lamprey: differential effects of $G_{A B A}$ and GABA $_{B}$ receptors. J. Neurophysiol., 69 (1993), pp. 647-657

Teräväinen and Rovainen, 1971. H. Teräväinen, C.M. Rovainen. Fast and slow motoneurons to body muscle of the sea lamprey. J. Neurophysiol., 34 (1971), pp. 990-998

Van Dongen et al., 1985a. P.A. Van Dongen, T. Hökfelt, S. Grillner, A.A. Verhofstad, H.W. Steinbusch, A.C. Cuello, L. Terenius. Immunohistochemical demonstration of some putative neurotransmitters in the lamprey spinal cord and spinal ganglia: 5-hydroxytryptamine-, tachykinin-, and neuropeptide-Y-immunoreactive neurons and fibers. J. Comp. Neurol., 234 (1985), pp. 501-522

Van Dongen et al., 1985b. P.A. Van Dongen, T. Hökfelt, S. Grillner, A.A. Verhofstad, H.W. Steinbusch. Possible target neurons of 5-hydroxytryptamine fibers in the lamprey spinal cord: immunohistochemistry combined with intracellular staining with lucifer yellow. J. Comp. Neurol., 234 (1985), pp. 523-535

Van Dongen et al., 1986. P.A. Van Dongen, S. Grillner, T. Hökfelt. 5-Hydroxytryptamine (serotonin) causes a reduction in the afterhyperpolarization following the action potential in lamprey motoneurons and premotor interneurons. Brain Res., 366 (1986), pp. 320-325

Viana Di Prisco et al., 1990. G. Viana Di Prisco, P. Wallén, S. Grillner. Synaptic effects of intraspinal stretch receptor neurons mediating movement-related feedback during locomotion. Brain Res., 530 (1990), pp. 161-166

Vinay et al., 1996. L. Vinay, J.Y. Barthe, S. Grillner. Central modulation of stretch receptor neurons during fictive locomotion in lamprey. J. Neurophysiol., 76 (1996), pp. 1224-1235

Wallén and Grillner, 1985. P. Wallén, S. Grillner. The effects of current passage on $\mathbf{N}$-methyl-d-aspartateinduced, tetrodotoxin-resistant membrane potential oscillations in lamprey neurons active during locomotion. Neurosci. Lett., 56 (1985), pp. 87-93

Wallén and Grillner, 1987. P. Wallén, S. Grillner. N-Methyl-d-Aspartate receptor-induced, inherent oscillatory activity in neurons active during fictive locomotion in the lamprey. J. Neurosci., 7 (1987), pp. 27452755

Wallén and Lansner, 1984. P. Wallén, A. Lansner. Do the motoneurones constitute a part of the spinal network generating the swimming rhythm in the lamprey? J. Exp. Biol., 113 (1984), pp. 493-497

Wallén and Williams, 1984. P. Wallén, T.L. Williams. Fictive locomotion in the lamprey spinal cord in vitro compared with swimming in the intact and spinal animal. J. Physiol. (London), 347 (1984), pp. 225-239

Wallén et al., 1985. P. Wallén, S. Grillner, J.L. Feldman, S. Bergelt. Dorsal and ventral myotome motoneurons and their input during fictive locomotion in lamprey. J. Neurosci., 5 (1985), pp. 654-661

Wallén et al., 1988. P. Wallén, K. Carlsson, A. Liljeborg, S. Grillner. Three-dimensional reconstruction of neurons in the lamprey spinal cord in whole-mount, using a confocal laser scanning microscope. J. Neurosci. Methods, 24 (1988), pp. 91-100

Wallén et al., 1989. P. Wallén, J.T. Buchanan, S. Grillner, R.H. Hill, J. Christenson, T. Hökfelt. Effects of 5hydroxytryptamine on the afterhyperpolarization, spike frequency regulation, and oscillatory membrane properties in lamprey spinal cord neurons. J. Neurophysiol., 61 (1989), pp. 759-768

Wallén et al., 1992. P. Wallén, Ö. Ekeberg, A. Lansner, L. Brodin, H. Tråvén, S. Grillner. A computer-based model for realistic simulations of neural networks. II. The segmental network generating locomotor rhythmicity in the lamprey. J. Neurophysiol., 68 (1992), pp. 1939-1950

Wickelgren, 1977. W.O. Wickelgren. Physiological and anatomical characteristics of reticulospinal neurones in lamprey. J. Physiol. (London), 270 (1977), pp. 89-114 
Wikström et al., 1995. M. Wikström, R. Hill, J. Hellgren, S. Grillner. The action of 5-HT on calcium-dependent potassium channels and on the spinal locomotor network in lamprey is mediated by 5-HT1A-like receptors. Brain Res., 678 (1995), pp. 191-199

Williams, 1992. T.L. Williams. Phase coupling by synaptic spread in chains of coupled neuronal oscillators. Science, 258 (1992), pp. 662-665

Williams et al., 1990. T.L. Williams, K.A. Sigvardt, N. Kopell, G.B. Ermentrout, M.P. Remler. Forcing of coupled nonlinear oscillators: studies of intersegmental coordination in the lamprey locomotor central pattern generator. J. Neurophysiol., 64 (1990), pp. 862-871

Windle, 1956. W.F. Windle. Regeneration of axons in the vertebrate central nervous system. Physiol. Rev., 36 (1956), pp. 427-440

Womble and Wickelgren, 1990. M.D. Womble, W.O. Wickelgren. Inhibition of a cAMP-dependent Ca-activated $\mathrm{K}$ conductance by forskolin prolongs $\mathrm{Ca}$ action potential duration in lamprey sensory neurons. Brain Res., 518 (1990), pp. 135-142

Wood and Cohen, 1981. M.R. Wood, M.J. Cohen. Synaptic regeneration and glial reactions in the transected spinal cord of the lamprey. J. Neurocytol., 10 (1981), pp. 57-79

Yin and Selzer, 1983. H.-S. Yin, M.E. Selzer. Axonal regeneration in lamprey spinal cord. J. Neurosci., 3 (1983), pp. $1135-1144$

Yin et al., 1981. H.-S. Yin, K.K. Wellerstein, M.E. Selzer. Effects of axotomy on lamprey spinal neurons. Exp. Neurol., 73 (1981), pp. 750-761

Yin et al., 1984. H.-S. Yin, S.A. Mackler, M.E. Selzer. Directional specificity in the regeneration of lamprey spinal axons. Science, 224 (1984), pp. 894-896

Yin et al., 1987. H.S. Yin, S.A. Mackler, M.E. Selzer. The axon reaction of lamprey spinal interneurons. Brain Res., 421 (1987), pp. 48-56 